\title{
La primera crisis financiera global del siglo XXI: origen, contención e implicaciones productivas y laborales*
}

\author{
Roberto Gutiérrez Rodríguez**
}

\section{RESUMEN}

La desregulación financiera de Estados Unidos y un grupo de países europeos cercanos a la economía estadounidense (particularmente Reino Unido), como resultado de la globalización económico-financiera de los años ochenta; la derogación de la ley Glass-Steagall, en 1999, y la reducción de las tasas de interés, a partir de 2002, fueron elementos clave para que se consolidara, a principios del siglo XXI una nueva arquitectura financiera internacional. Ésta terminó por desencadenar la crisis de 2008-2009, iniciada en Estados Unidos e irradiada casi inmediatamente a Europa y otras regiones del mundo, en una cadena de causalidad en que quedaron implicadas virtualmente todas las instancias del sistema financiero. Aunque los gobiernos de Bush, primero, y Obama, después, reaccionaron pronto, las consecuencias para la economía global fueron severas y siguen presentes, debido a la doble recesión iniciada en 2012 en España, Reino Unido, Italia y otros países europeos (de Grecia nunca se fue), para cuya erradicación se hizo necesario lo mismo el concurso del sistema financiero internacional que la profundización de políticas de ajuste cuyos costos laborales son evidentemente rigurosos y de reversión lenta.

Palabras clave: crisis financiera, desregulación financiera, activos tóxicos, programas de rescate, mercado laboral

Clasificación JEL: F01.

\begin{abstract}
Financial deregulation in USA and a group of European countries close to such an economy, particularly UK, as a consequence of the economic and financial globalization of the 1980s, the Glass-Steagall Act repeal, in 1999, and the lowering of interest rates from 2002 onwards, were key elements for the design of a new international financial architecture. The direct effect of all this was the crisis of 2008-2009, which started in USA and was eradiated almost immediately to Europe and other regions of the world, through a chain of causation that involved virtually all instances of the financial system. Although Bush and Obama administrations reacted swiftly, the consequences for the global economy were paramount, and are still present due to the beginning in 2012 of a double-dip recession in Spain, UK, Italy and other European countries (it never left Greece) and for whose eradication the participation of the international financial system was required, as well as the deepening of adjustment policies, with profound and hard to reverse labor costs.
\end{abstract}

Keywords: financial crisis, financial deregulation, toxic assets, bailout, labor market. JEL classification: F01.

\footnotetext{
* Fecha de recepción: 19/06/2012. Fecha de aceptación: 03/06/2013.

** Profesor-investigador del Departamento de Economía de la Universidad Autónoma Metropolitana-Iztapalapa.

El autor se siente comprometido con un grupo interuniversitario constituido por instituciones académicas del país y el extranjero, entre ellas la UAM, la UNAM, el Colmex y la Udeg, en el que se discutió la crisis de 2008-2009 y en el que fueron participantes asiduos José Luis León (UAM-X), José Luis Estrada (UAM-I) y Teresa Gutiérrez Haces (UNAM). De la misma manera, agradece a dos
} 


\section{INTRODUCCIÓN}

Una debilidad esencial de la arquitectura financiera internacional que se diseñó a partir del surgimiento de las instituciones abocadas a la reconstrucción de las naciones afectadas por la segunda Guerra Mundial, al financiamiento del desarrollo económico y a enfrentar las crisis de balanza de pagos (Banco Mundial, Fondo Monetario Internacional y bancos regionales de desarrollo) ha sido su proclividad a la desregulación. Ésta mostró sus verdadero rostro a partir de la década de los ochenta, con la introducción de las tecnologías de la información y la comunicación (TIC), las cuales apuntalaron una nueva fase de la mundialización originalmente conceptualizada por Braudel (1979), sustentada en los crecientes flujos comerciales de postguerra, potenciados con la firma de acuerdos comerciales regionales, y en los inusitados flujos de capital físico y financiero, asociados tanto al comercio como a la especulación. A esto se sumó la transferencia entre países - no obstante, muy regulada- de tecnología, conocimientos y fuerza de trabajo, en un entorno ávido de capital y carente de políticas industriales.

En el presente trabajo no sólo se argumenta que la primera crisis financiera del siglo XXI, surgida en Estados Unidos (EU), es producto del proceso de globalización, sino que el propio sistema regulatorio estadounidense -más bien la ausencia de un marco regulatorio adecuado- la precipitó. En este contexto, el punto central es que la titularización ${ }^{1}$ de créditos hipotecarios otorgados por la banca comercial a tasas por arriba de las del mercado, en virtud del riesgo que implicaba la baja solvencia de sus destinatarios, se llevó a cabo preponderantemente en un mercado financiero paralelo que se expandió gracias a operaciones sobre el mostrador (over-the-counter) sustentadas en una nueva arquitectura fi-

dictaminadores anónimos sus acertadas observaciones, así como al arquitecto Hugo de Labra Fernández por las innumerables charlas sobre el tema. El resultado final, empero, sigue siendo su plena responsabilidad.

${ }^{1}$ Se entiende por titularización (securitization) la "ingeniería financiera" consistente en mezclar varios tipos de deuda contractual - hipotecas residenciales, hipotecas comerciales, préstamos para compra de automóviles, adeudos de tarjetas de crédito - y promesas de pago como bonos, títulos vencidos y obligaciones hipotecarias colateralizadas (СMO, por collateralizad mortgage obligation), y colocarlas entre inversionistas institucionales a los que se cubren, de acuerdo con lo pactado, el principal y los intereses. Los compromisos respaldados por hipotecas reciben el nombre de valores respaldados por hipotecas (MBS, por mortgage-backed securities), mientras que los respaldados por otro tipo de activos se conocen como valores respaldados por activos (ABS, por asset-backed securities). Dentro de los inversionistas institucionales se cuentan los bancos de inversión, los fondos de pensiones, los fondos de protección (hedge funds) y otros vehículos especiales de inversión (special investment vehicles). 
nanciera caracterizada por la circulación de vehículos especiales de inversión altamente favorecidos por las entidades calificadoras, con ausencia de reglas y contando con el supuesto aseguramiento de entidades insuficientemente capitalizadas. ${ }^{2}$ Esta cadena de causalidad, en que quedaron implicadas virtualmente todas las instancias financieras; su irradiación a las esferas productiva y laboral; los instrumentos monetarios, financieros y de coordinación internacional puestos en operación para superarla, y las previsiones del comportamiento de la economía mundial hacia 2014 pretenden ser las principales líneas de análisis de este artículo.

Tales vehículos fueron creados por los bancos comerciales, empaquetados por los bancos e instituciones de inversión y puestos en circulación por la acción de ambas instancias, en una asociación que se hizo posible gracias a que sus intereses convergieron al permitirse, desde 1999, la fusión de las bancas comercial y de inversión, y la expansión de los vehículos especiales de inversión, entre ellos los fondos de protección (hedge funds). Esto propició el avance sin precedente de los instrumentos financieros conocidos como derivados, cuyo valor subyacente incluía créditos concedidos a familias de bajos recursos (familias subprime) y a las que, debido al riesgo, se cobraban tasas de interés más altas que al resto de acreditados. ${ }^{3}$ Curiosamente, tanto los directivos como los corredores (brokers) de la banca y las casas de bolsa tenían poca certidumbre sobre la mecánica de operación y las consecuencias para el ahorro privado e institucional de dichos instrumentos, así como para el sano funcionamiento del sistema financiero; empero, los promovieron porque entre más colocaciones lograban más aumentaban sus salarios y más altos bonos de actuación y primas recibían.

Así, se consolidaron grandes conglomerados financieros, cuyas ganancias se potenciaron al prestar varias veces los mismos créditos fuera de sus hojas de balance. Dicha dinámica, en la que estaba involucrado todo el sistema financiero de EU, y que adoptaron con gusto varios países de Europa, principalmente Reino Unido, sumándoseles las calificadoras de riesgo, avanzó tanto y generó tal cantidad de expectativas que hubo de llegar a un punto de no retorno, como había sucedido con todas las crisis financieras previas. La primera llamada de atención fue el colapso de Bear Stearns y su inmediata adquisición por parte de JP Morgan Chase a precio de ganga, en marzo de 2008; cinco meses después sobre-

\footnotetext{
${ }^{2}$ El hecho de que en la fase de expansión posterior a 2002 los instrumentos titularizados se hayan considerado de bajo riesgo atrajo mucho a los inversionistas institucionales que reempaquetaron los activos en la forma de obligaciones colateralizadas de deuda (CDO, por collateralizad debt obligation).

${ }^{3}$ A estas familias también se les conoció como familias NINJA (no income, no job, no assets).
} 
vino la quiebra de Lehman Brothers. Nótese que estas tres instituciones formaban parte de los mayores bancos del país y que para JP Morgan Chase era muy importante subir a la primera posición de la lista de bancos de inversión mediante la adquisición de Bear Stearns, después de que en 2000 había emergido como institución financiera global gracias a la fusión entre JP Morgan and Co., banco de inversión, con Chase Manhattan Corporation, banco comercial.

A tal tenor, este trabajo centra la atención en el hecho de que la crisis surgió a consecuencia de una gran desatención de problemas estructurales. El primero y más visible es la desregulación del sistema financiero de EU. ${ }^{4} \mathrm{El}$ segundo es la forma de financiamiento de los así llamados déficit gemelos de dicho país, que en años previos a la crisis habían alcanzado niveles insostenibles: el déficit de cuenta corriente se ubicó en $6 \%$ respecto al producto nacional bruto (PNB), en una tendencia creciente que arrancó a inicios de los años noventa, cuando el país se convirtió en exportador neto de capitales, y el déficit neto del sector público se estableció en $4.8 \%$, lo que refleja un nivel de gastos presupuestales muy superior al de los ingresos. Al solventarse ambos con deuda interna y externa, vía colocación de bonos del Tesoro, se dejó a los contribuyentes una carga que pasarán muchos años antes de que se salde, con las implicaciones que tendrá para la competitividad de largo plazo del país, así como para el valor real del dólar frente a las monedas más sólidas. Tales desequilibrios contribuyen a acelerar el proceso de transición del poder económico mundial que se inició en los años noventa y que desembocará en que el PNB nominal de China sea el primero del planeta alrededor de 2027 (Ward, 2011).

Así, la primera sección se aboca a analizar el origen de la crisis, incluyendo las condiciones de exuberancia financiera que la propiciaron. La segunda se centra en la forma y condiciones en que ésta se presentó. La tercera da cuenta de los montos y modalidades del rescate por parte de los gobiernos de George Bush y Barak Obama. La cuarta hace un repaso de la cadena de causalidad del problema, que del sector financiero pasó al de la economía real y dio lugar a elevados niveles de desempleo y exclusión social. Se cierra con las conclusiones.

\section{EL ORIGEN DE LA CRISIS}

La crisis estadounidense de 2008-2009 tiene un carácter eminentemente financiero, cuyas raíces se hunden en al menos tres hechos: la consolidación de la

\footnotetext{
${ }^{4}$ EU es responsable de $23 \%$ del producto mundial y de alrededor de un tercio de los flujos de capital internacionales.
} 
globalización, durante la década de los ochenta; la eliminación de la ley GlassSteagall, en 1999, y las medidas posteriores a la recesión asociada a la burbuja tecnológica (2001-2002), instrumentadas por el Federal Reserve System, el banco central de EU (conocido coloquialmente en español como la Reserva Federal y en inglés como Fed).

La década de los ochenta marcó el inicio de la globalización, no en el sentido histórico que le da Fernand Braudel (1979), asociado al comercio hacia y desde las principales ciudades-Estado europeas alrededor del siglo XIV (Venecia, Génova, Amberes, Ámsterdam, etc.) y a los posteriores Estados-nación, sino en el sentido moderno, que tiene que ver con el uso de las TIC para facilitar el comercio y, sobre todo, para hacer más expeditos los flujos de capital (Gutiérrez, 2002).

En 1999, cuando finalizaba la segunda administración de William Clinton, se modificó el sistema estadounidense de control financiero Glass-Steagall, que había estado vigente desde la conclusión de la Gran Depresión. ${ }^{5}$ Esto permitió la fusión de bancos comerciales con bancos de inversión, algo que también promovieron diversas instituciones financieras de Europa, ante la omisión de los Acuerdos de Basilea II, de 2004, consistentes en el establecimiento de reglas de capitalización de la banca que garantizarían el buen funcionamiento del sistema a nivel internacional. Estas omisiones dieron paso a lo que se conoce como nueva arquitectura financiera, cuya esencia es el surgimiento de un sistema financiero paralelo, provisto con una serie de instrumentos de inversión excesivamente complejos que el público ahorrador, lo mismo físico que institucional, no fue capaz de entender y que los corredores y funcionarios de la banca tampoco pudieron explicar, menos prever su colapso.

En respuesta a la crisis bursátil de 2001 (burbuja tecnológica) el titular de la Fed, Alan Greenspan, acordó con su Consejo de Gobernadores la disminución de la tasa de interés real a niveles sin precedentes desde la Gran Depresión: el rendimiento de la tasa de fondos federales bajó de casi $4 \%$ a finales de 2000 a niveles negativos entre inicios de 2003 y principios de 2006, tocando fondo entre las postrimerías de 2004 e inicios de 2005 ( $-2 \%)$, como se aprecia en la gráfica 1.

\footnotetext{
${ }^{5}$ De acuerdo con la ley Glass-Steagall los bancos comerciales quedaron, desde 1933, año de inicio de su aplicación, a cargo de los créditos comerciales y al consumo, y se les indujo, mediante regulaciones muy estrictas, a evitar préstamos riesgosos con el fin de disponer de liquidez para apoyar eventuales contingencias de otras áreas del sistema, entre ellas los bancos de inversión. Es decir, se les asignó el paso previo al de prestamista de último recurso, que recaía en la Fed y la Federal Deposit Insurance Corporation (FDIC).
} 
Gráfica 1. Tasa de real de fondos federales de EU, enero de 2000-mayo de 2009

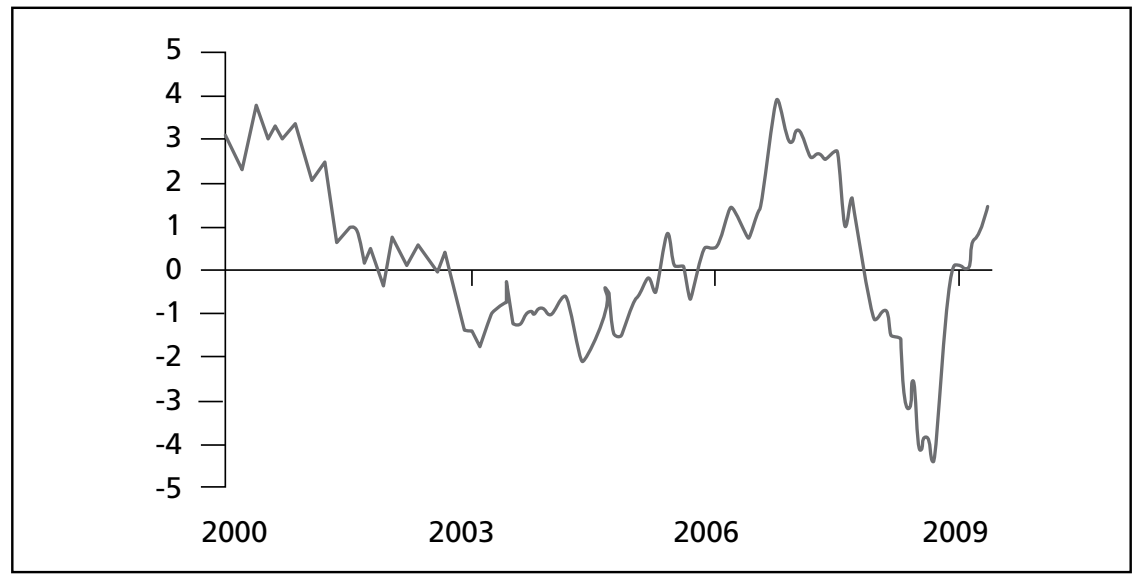

Fuente: Elaboración propia con base en cifras de Bloomberg.

Este abaratamiento del crédito, que restaba ganancias por intermediación financiera a los bancos comerciales, los indujo a seguir por lo menos dos cursos de acción. Por una parte, reforzaron el proceso de fusión que habían iniciado en 1999 con grandes bancos de inversión, entidades financieras especializadas en el diseño y colocación de instrumentos de financiamiento de largo plazo, a través de la bolsa de valores o en forma privada para un emisor determinado. Esto no sólo potenciaba las operaciones de la banca mediante la creación o reforzamiento de superestructuras financieras, sino que les brindaba un mayor margen de maniobra. ${ }^{6}$ Asimismo, los alejaba de la regulación de Basilea II en materia de requerimientos de capital necesarios para proteger a sus acreditados frente a riesgos financieros y operativos.

Por otra parte, se sirvieron de la misma banca de inversión para titularizar su deuda, es decir empaquetar los créditos hipotecarios y de otro tipo que habían otorgado, y que tenían calificación desde excelente (AAA) hasta muy mala (subprime), de forma tal que resultaba muy difícil determinar el grado de riesgo de cada paquete. ${ }^{7}$ Los instrumentos de titulación más conocidos, y a la larga más

${ }^{6}$ Entre los principales bancos de inversión potenciados con estas acciones en EU estuvieron Goldman Sachs, Morgan Stanley, Merrill Lynch, JP Morgan Chase, Lehman Brothers y Bear Stearns. En Europa no se podían quedar atrás USB, Credit Suisse, ABN AMRO, HSBC, BNP PARIBAS y Deutsche Bank.

${ }^{7}$ A pesar de su debilidad intrínseca, los fondos de protección conseguían calificaciones AAA de las grandes calificadoras de riesgo, Moody's, Fitch Ratings, Standard \& Poor's, instituciones que 
problemáticos, fueron los valores respaldados por hipotecas (MBS, por mortage backed securities), las obligaciones de deuda colateralizadas (CDO, por collateralizaed debt obligations), y las obligaciones de préstamo colateralizadas (CLO, por collateralizaed loan obligations). Sus principales características eran flexibilidad, no estar sujetos a regulación y encontrarse alejados de las hojas de balance de los bancos, lo que permitió a las instituciones financieras prestar el mismo dinero varias veces. Con ello, se abrió paso a un sistema de banca paralela que se expandió extraordinariamente y que, de acuerdo con Boyer (2012), llegó a representar en EU 10 veces su PNB.

Sin descartar su eventual incobrabilidad, los bancos consideraron que la masificación de los créditos hipotecarios subprime era lucrativa en virtud del aumento constante del precio de las viviendas desde hacía varias décadas (tan sólo entre 1997 y 2007 el índice s\&P Case-Shiller de precios de la vivienda más que se duplicó en términos reales, como indica la gráfica 2), lo que aseguraba que en caso de que los clientes cayeran en insolvencia la venta de la propiedad permitiera recuperar el crédito.

Gráfica 2. Índice S\&P Case-Shiller de precios de la vivienda, enero de 1987-abril de 2009

(base enero $2005=100$ )

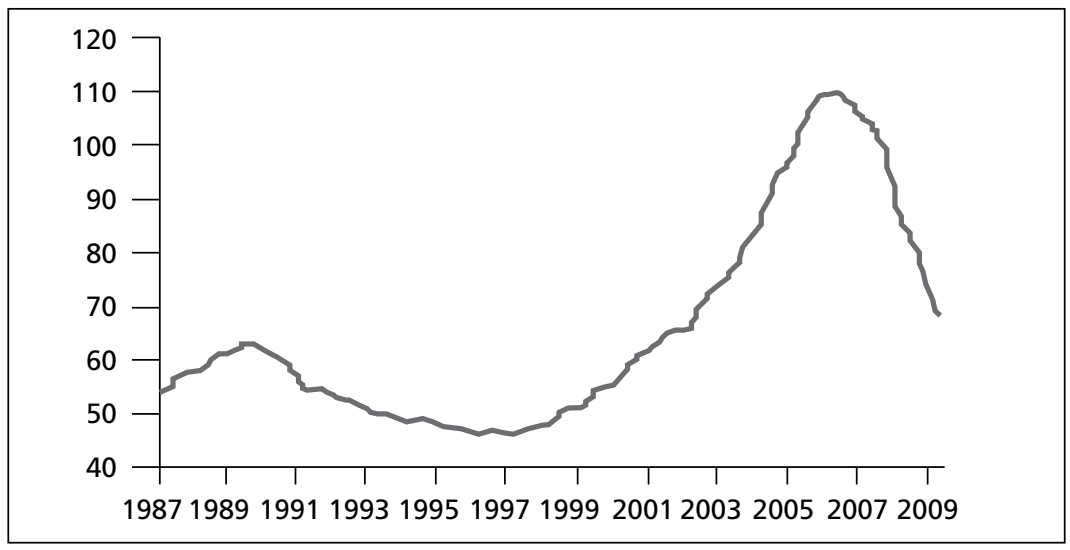

Fuente: Elaboración propia con base en cifras de Standard \& Poor's.

perseguían incentivos perversos: por una parte, calificaban su grado de riesgo; por otra, asesoraban a las compañías emisoras, a cambio de un pago, con el fin de lograr su mejor conformación y colocación en el mercado. 
Ya titularizados, los paquetes de hipotecas y de otro tipo de deuda obtenían el respaldo de las compañías aseguradoras, destacadamente el American Investment Group (AIG), y las compañías monoline, entre ellas AMBAC Assurance Corp. y Financial Security Assurance Inc., muy débilmente reguladas y diseñadas originalmente para asegurar los mercados de bonos municipales, que en EU conforman un espectro muy amplio.

Los fondos de protección eran entonces adquiridos por los bancos de inversión, que incluso podían retitularizarlos. A partir de esto, los bancos comerciales, las aseguradoras y otros actores financieros negociaban los títulos con ahorradores físicos e institucionales, incluyendo de manera prominente a las compañías administradoras de fondos de pensiones. Paralelamente, los bancos de inversión utilizaban esos activos como garantía para pedir créditos adicionales y apalancar más operaciones financieras. Se creaba así una enorme cantidad de activos que, por muy sofisticados que fuesen, tenían como último eslabón de la cadena a las familias de bajos recursos; es decir que las posibilidades de incumplimiento, aunque no se reconocieran, eran muy altas.

Cabe recordar al respecto que las probabilidades de incumplimiento de los instrumentos de inversión se determinaban calculando el número de incumplimientos y de pérdidas por esta causa en cada tramo de inversión, a partir de la correlación histórica de los activos, la cual se manejaba con una descomposición Cholesky. Las pérdidas reales se distribuían al correr un número de $10000 \mathrm{a}$ 100000 de la simulación Monte Carlo. En correspondencia con el modelo BlackScholes-Merton, desarrollado en los años setenta para determinar el grado de riesgo de una inversión a partir del precio del activo subyacente, se generaba un número aleatorio de incumplimientos. La complejidad para calcular el pago esperado del incumplimiento, indispensable en la determinación del precio de instrumentos como las CDO, crecía exponencialmente con el número de activos de referencia, es decir las hipotecas originales.

Dados los millones de hipotecas contenidas en las CDO, ninguna empresa tenía el tiempo ni el incentivo para calcular el riesgo inherente a dicho instrumento, e incluso no existía un modelo adecuado para el efecto, debido a la complejidad y falta de linealidad de la correlación entre el valor del CDO y las hipotecas. ${ }^{8}$ Esto implica que pequeños cambios en los precios de las hipotecas en

\footnotetext{
${ }^{8}$ Una matriz definida positiva puede descomponerse como el producto de una matriz triangular inferior y la traspuesta de la matriz triangular inferior, la cual será el triángulo de Cholesky de la matriz original positiva definida. El resultado de Cholesky ha sido extendido a matrices con entradas complejas y es una manera de resolver sistemas de ecuaciones matriciales a partir de la factori-
} 
ocasiones no afectan el precio de las $\mathrm{CDO}$; pero grandes cambios conducen a enormes e impredecibles variaciones (Crotty, 2008). En el extremo, el esquema tenía vicios parecidos a los del modelo piramidal de Ponzi, ya que los altos rendimientos se financiaban con los pagos de las hipotecas, lo mismo de familias solventes que familias de bajos recursos, y éstas fueron las que más se incorporaron al sistema entre 2003 y 2007.

Dado que en todo este marco existe una enorme desregulación financiera, el número de transacciones que involucraban los vehículos especiales de inversión creció de manera exponencial, en una tendencia que se inició una vez superada la burbuja tecnológica de 2001-2002. ${ }^{9}$ Y como el precio de estos instrumentos subía sin cesar a partir de 2004, se creó la falsa imagen de que las ganancias fáciles iban a continuar por mucho tiempo. Es decir, se vivió un periodo de exuberancia financiera similar a los que habían precedido a la mayoría de las depresiones del siglo xx y principios del XxI, desde la Gran Depresión de 1929-1932 hasta la crisis de 2001-2002, aunque con un volumen de recursos mucho mayor y con instrumentos casi desconocidos en otras épocas.

\section{La exuberancia financiera previa a la crisis}

La desregulación financiera previa a la crisis, combinada con las bajas tasas de interés impuestas por la Fed, se tradujo en una alta circulación de instrumentos no regulados, con especial énfasis en los fondos de protección y, dentro de éstos, los MBS, las cuales duplicaron en EU su valor nominal entre 2001 y 2008, hasta llegar a 7.4 billones de dólares, equivalentes a más de 50\% del PNB de dicho país. Éstos servían de respaldo para derivados como las CDO, lo que generaba una cadena sumamente compleja con enorme capacidad de expansión. Por ejemplo,

zación LU con una pequeña variación. Cualquier matriz cuadrada A con pivotes no nulos puede expresarse como el producto de una matriz triangular inferior $\mathbf{L}$ y una matriz triangular superior $\mathbf{U}$; esto recibe el nombre de factorización LU. Sin embargo, si A es simétrica y definida positiva, se pueden escoger factores tales que $\mathbf{U}$ es la transpuesta de $\mathbf{L}$, lo que se llama descomposición o factorización de Cholesky. Tanto la descomposición $\mathbf{L U}$ como la descomposición de Cholesky se usan para resolver sistemas de ecuaciones lineales. Cuando es aplicable, la descomposición de Cholesky es dos veces más eficiente que la descomposición LU. La descomposición de Cholesky se usa comúnmente en el método Monte Carlo para simular sistemas con variables múltiples correlacionadas: la matriz de correlación entre variables es descompuesta para obtener la triangular inferior $\mathbf{L}$. Aplicando ésta a un vector de ruidos simulados incorrelacionados, u produce un vector Lu con las propiedades de covarianza del sistema a ser modelado.

${ }^{9}$ De acuerdo con el National Bureau of Economic Research (NBER), la recesión en cuestión empezó en marzo de 2001 y concluyó en igual mes de 2002 (Gutiérrez, 2004). 
hasta 150 MBS se empaquetaban en una CDO. A su vez, una CDO al cuadrado $\left(\mathrm{o}_{\mathrm{CDO}}{ }^{2}\right.$ ), se creaba a partir del uso de otros tramos de CDO, tomados como colaterales. Una $\mathrm{CDO}^{3}$ usaba tramos de $\mathrm{CDO}$ y $\mathrm{CDO}^{2}$. Entre más elevada es la potencia que tienen las CDO más difícil es modelar su comportamiento debido a que a su interior se pueden repetir las hipotecas. Además, hay CDO sintéticas, que usan credit defaul swaps (CDS) u otros instrumentos de crédito como sus colaterales. Debido a esta reproducción de instrumentos, el valor nominal de los CDs pasó de 6 billones de dólares, en diciembre de 2004, a 62 billones tres años después (Crotty, 2008), monto que representaba 4.5 veces el PNB de EU.

Así, la participación de la intermediación financiera no tradicional respecto a la total pasó de $23.6 \%$ en 1986 a $44.6 \%$ en 2006 , como muestra el cuadro 1 , con un crecimiento espectacular de los títulos respaldados por activos, las sociedades de inversión y los bancos de inversión. Además, en la sección de entidades tradicionales se observa un incremento sustancial de las empresas privadas patrocinadas por el Estado, fundamentalmente las orientadas al crédito hipotecario, Fanni Mae y Freddie Mac, cuya participación pasó de 3.4\% a 5\% en igual periodo.

\section{Cuadro 1. Participación de las entidades financieras de EU en la intermediación del país}

\begin{tabular}{lrr}
\hline & 1986 & 2006 \\
\cline { 2 - 3 } & \multicolumn{2}{c}{ Porcentaje } \\
\cline { 2 - 3 } Bancos, entidades de ahorro y préstamo, & 41.1 & 22.1 \\
y cooperativas de crédito & 12.5 & 10.2 \\
Seguros & 19.4 & 17.7 \\
Fondos de pensiones & 3.4 & 5.0 \\
Empresas patrocinadas por el Estado* & 76.4 & 55.4 \\
Total tradicional & 6.0 & 14.1 \\
Emisores de títulos respaldados por activos & 7.4 & 18.3 \\
Sociedades inversión & 1.8 & 4.8 \\
Bancos de inversión & 8.4 & 7.4 \\
Otros & 23.6 & 44.6 \\
Total no tradicional & 100.0 & 100.0 \\
\hline Intermediación financiera total & & \\
\hline
\end{tabular}

* Instituciones financieras que proveen crédito a áreas específicas de la economía, como el sector hipotecario o agrícola. Destacan los Federal Home Loan Banks, Freddie Mac y Fannie Mae.

Fuente: Board of Governors of the Fed (s.f.). 
De manera paralela, el valor nominal de los activos de los bancos globales gigantes de Reino Unido pasó de 10 billones de dólares en 2000 a 23 billones en 2007 , lo que implica un avance promedio anual de $15 \%$ y un múltiplo respecto al PNB del último año de 8.3. Este dinamismo se dio, fundamentalmente, por la expansión de los MBS y las CDO, mientras que el capital regulatorio de los bancos apenas aumentó $20 \%$ en todo el periodo (Crotty, 2008). Con ello, la relación activos/capital adquiría dimensiones explosivas, lo mismo en eU y Reino Unido que en Suiza, Francia, Alemania y otros países que poseen grandes conglomerados financieros.

Por otra parte, la tasa hipotecaria para créditos a todos los plazos acusó un descenso sostenido a partir de diciembre de 1994, para ubicarse a mediados de 2004 en sus niveles más bajos de toda la historia: $3.25 \%$ a un año, $4.75 \%$ a 15 años y $5.25 \%$ a 30 años (gráfica 3), lo que resultaba muy atractivo si se comparaba con la tasa fondos federales real, exhibida en la gráfica 1. Esto, aunado a las facilidades de financiamiento otorgadas por los bancos, contribuyó al crecimiento de los créditos subprime, cuya participación en los nuevos créditos hipotecarios concedidos por la banca pasó de $6 \%$ en 2000 a 21\% en 2006 (us Census Bureau, 2008), alcanzando un rango de entre $6.75 \%$ y $7.75 \%$ en junio de 2006 (gráfica 3), para mantenerse así hasta junio de 2007.

Gráfica 3. Tasa de interés hipotecaria para primeros contratos a 1, 15 y 30 años, diciembre de 1992-diciembre de 2010

(porcentaje)

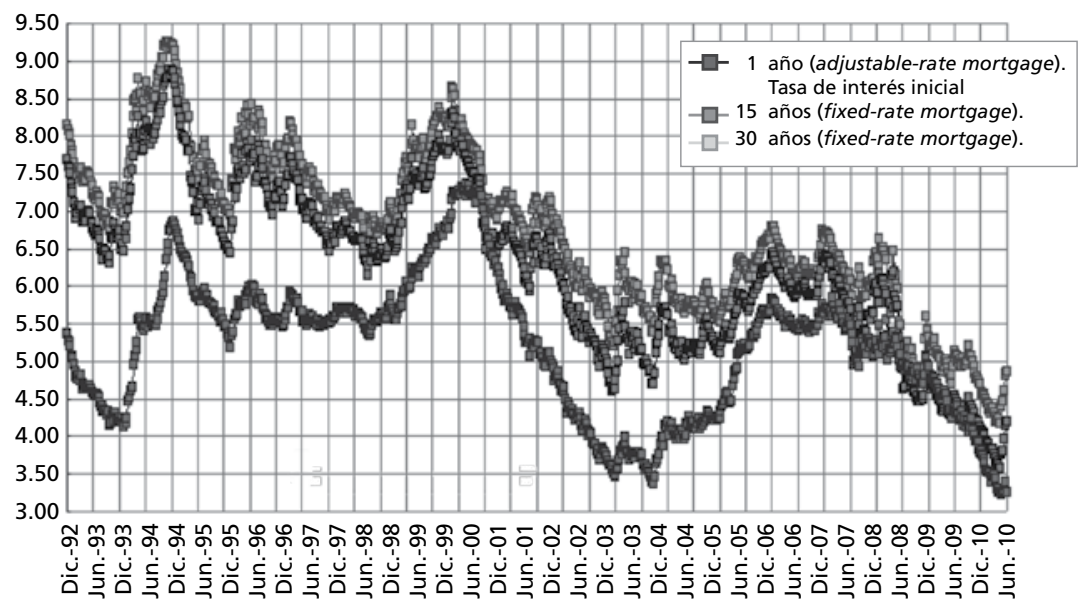

Fuente: Mortgage-x (s.f.). 
El relajamiento de la política monetaria, con bajas tasas de interés que conducen al sobreendeudamiento de los agentes económicos y los vuelven proclives a tomar riesgos, sobre todo en el mercado de capitales, se ha tipificado ya como un patrón de euforia financiera que empieza entre tres y cinco años antes de la irrupción de una crisis. Así sucedió con la iniciada el "lunes negro" del 19 de octubre de 1987, que llevó al índice Dow Jones a mínimos históricos. Lo mismo pasó con la que estalló en agosto de 1982, una de las más prolongadas de que se tenga memoria y que obligó a México a decretar una moratoria técnica de su deuda externa después de haberse sobreendeudado gracias al abundante crédito y el bajo nivel de la tasa de interés internacional, lo que se revirtió a partir de 1979, cuando la Fed la triplicó, dando inicio formal a la crisis financiera de los años ochenta (Gutiérrez, 1993). Y también se observó con la crisis de la burbuja tecnológica, iniciada en marzo de 2001.

\section{Gráfica 4. Promedio Industrial Dow Jones, enero de 2001-diciembre de 2010}

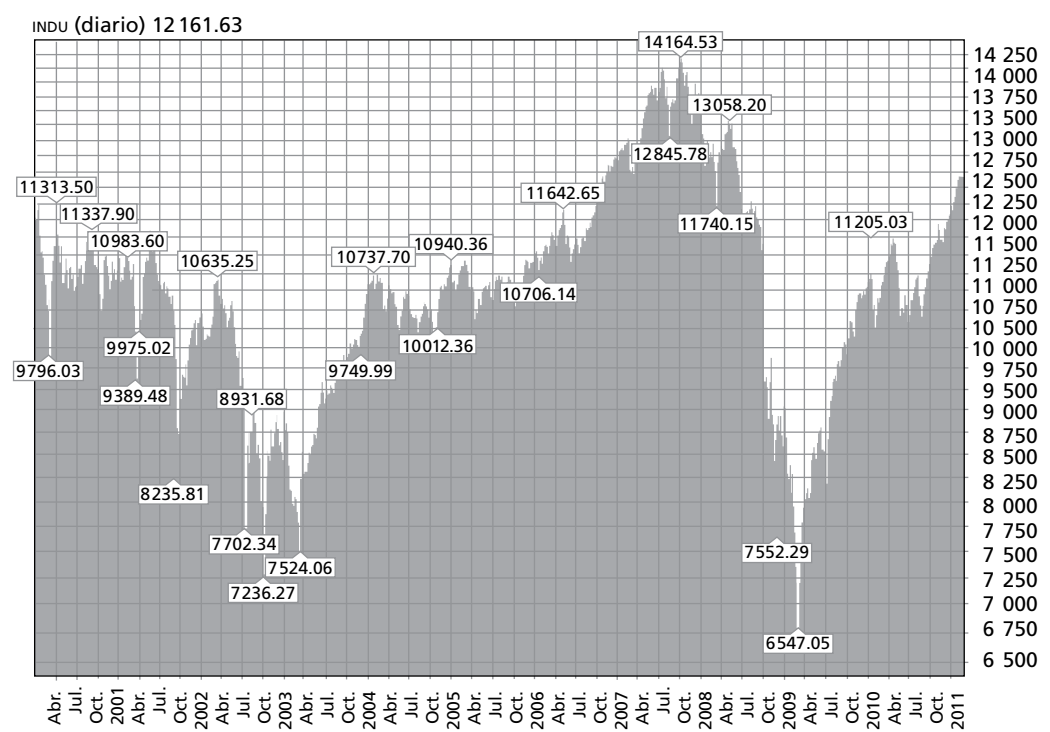

Fuente: Elaboración propia con base en información de Dow Jones.

Las bajas tasas de interés, combinadas con el dinero caliente, provocan que los ahorradores se refugien en instrumentos con alto rendimiento y un enorme riesgo; de ahí la relación inversa que existe, en condiciones normales, entre la tasa de interés pasiva, por una parte, y la compra de acciones en el mercado bursátil y el rendimiento de los bonos, por otra. Al amparo de este sistema de 
banca paralela, e incrustados en el sistema de Wall Street, se desarrollaron algunos fondos de tipo piramidal (Ponzi), como los de Madoff y Stanford, sobre los que se volverá más adelante. Ello propició, asimismo, el crecimiento exorbitante de las bolsas de valores del mundo. Por ejemplo, el índice Dow Jones, que después de la crisis de la burbuja tecnológica de 2001-2002 se había contraído hasta un valle de casi 7200 puntos, en octubre de 2002, resurgió hasta un pico de más de 14000 puntos en octubre de 2007, como muestra la gráfica 4.

En este marco, los flujos de capital financiero crecieron aceleradamente en todo el mundo. Como muestra el cuadro 2, los países desarrollados lo mismo invirtieron grandes cantidades en otros países desarrollados entre 2000 y 2007 que recibieron recursos externos para invertirse en su territorio. Muchos eran evidentemente tóxicos, aunque por la forma en que estaban empaquetados resultaba difícil detectarlos. Asimismo, un grupo importante de países emergentes incrementó su dependencia de los activos que llegaban de fuera, sin conocer su grado de toxicidad.

El auge del sistema financiero, junto con el sobrecalentamiento de la economía mundial entre 2004 y principios de 2008, contagió paulatinamente los mercados de materias primas, o commodities, desde minerales hasta granos básicos, que ya para los años ochenta se habían incorporado en su totalidad al torbellino de la especulación, a través de la determinación de sus precios futuros en el mercado de Nueva York. Así, se expandieron de manera extraordinaria los precios de trigo, maíz, sorgo, cobre, zinc, petróleo y, finalmente, oro y plata. El promedio de los precios de todas las materias primas se presenta en la gráfica 5, donde se observa su expansión inusitada durante todo 2007 y la primera mitad de 2008, para caer en la segunda mitad y luego retomar su ritmo ascendente. Aquí debe resaltarse el hecho de que la cotización de los dos principales crudos marcadores del mundo, el West Texas Intermediate y el Brent, pasaron de menos de 30 dólares por barril en 2002 a cerca de 160 dólares a mediados de 2008: una “joroba” más pronunciada que la de la gráfica 5 para el mismo periodo, en cuya última parte se inició un gran ascenso del oro, primero, y la plata, después. ${ }^{10}$

\footnotetext{
${ }^{10}$ Los mercados financieros se comunican intrínsecamente con la parte real de sus propias economías y con los mercados financieros del mundo. Así, por una parte, los títulos de las principales empresas del mundo cotizan en las bolsas de valores de Nueva York, Londres, Frankfurt, París, Tokio, Hong Kong; por otra, los precios a futuro de las materias primas y las divisas se determinan en Nueva York, Chicago, Londres y otros mercados. Por tanto, cuando las acciones de los bancos, los fondos de protección y los derivados subían, también lo hacían los precios a futuro de las mate-
} 
Cuadro 2. Recursos financieros de residentes y bancos de países desarrollados invertidos en el exterior $y$ de residentes y bancos externos invertidos en su territorio y en economías emergentes (continúa)

\begin{tabular}{|c|c|c|}
\hline País & 2000 & 2007 \\
\hline Activos de residentes del país en el exterior & \multicolumn{2}{|c|}{ Porcentaje del PIB } \\
\hline Estados Unidos & 63.6 & 127.8 \\
\hline Unión Europea & 85.8 & 154.3 \\
\hline Japón & 68.8 & 118.4 \\
\hline Activos de residentes del exterior en el país & \multicolumn{2}{|c|}{ Porcentaje del PIB } \\
\hline Estados Unidos & 77.1 & 145.4 \\
\hline Unión Europea & 110.4 & 166.9 \\
\hline Japón & 42.4 & 69.9 \\
\hline Activos de bancos del país en el exterior & \multicolumn{2}{|c|}{ Porcentaje del PIB } \\
\hline Estados Unidos & 24.3 & 47.0 \\
\hline Japón & 13.1 & 21.4 \\
\hline Alemania & 38.9 & 68.9 \\
\hline Francia & 38.6 & 76.2 \\
\hline Reino Unido & 57.3 & 130.2 \\
\hline Suiza & 109.7 & 179.2 \\
\hline Islandia & 35.4 & 364.3 \\
\hline Austria & 31.3 & 70.8 \\
\hline Activos de bancos del exterior en el país & \multicolumn{2}{|c|}{ Porcentaje de los activos } \\
\hline Europa Central y del Este* & 36.2 & 49.3 \\
\hline República Checa & 48.9 & 97.0 \\
\hline Estonia & 73.1 & 97.0 \\
\hline Hungría & 63.5 & 76.5 \\
\hline Polonia & 37.8 & 70.5 \\
\hline Rusia & 11.5 & 17.2 \\
\hline Eslovaquia & 54.6 & 92.0 \\
\hline Asia sin China e India* & 10.3 & 33.2 \\
\hline China & 0.0 & $2.0 * *$ \\
\hline India & 2.0 & 9.8 \\
\hline
\end{tabular}

rias primas; de manera correspondiente, cuando los primeros empezaron a caer, los segundos lo hicieron, desde el petróleo hasta los cereales. 
Cuadro 2. Recursos financieros de residentes y bancos de países desarrollados invertidos en el exterior $y$ de residentes y bancos externos invertidos en su territorio y en economías emergentes (concluye)

América Latina*

Argentina

Brasil

Chile

México

Perú

Venezuela
28.4

47.8

26.4

38.4

28.5

66.1

20.7
66.9

24.0

23.0

59.6

82.0

48.5

26.0

* Participación extranjera por región ponderada calculando_el total de activos bancarios de cada país.

** Con datos de 2004.

Fuente: Banco de México (2009, p. 19).

Paralelamente, empezó a subir la tasa de riesgo de los principales bancos de inversión, lo que quiere decir que cada vez era menor el capital contable de que disponían respecto a los activos comprometidos, como muestra la gráfica 6 en los casos de UBS, Morgan Stanley, Lehman Brothers y Merrill Lynch.

Gráfica 5. Promedio de precios de Goldman Sachs para materias primas, 2000-2010 (base $2000=100)$

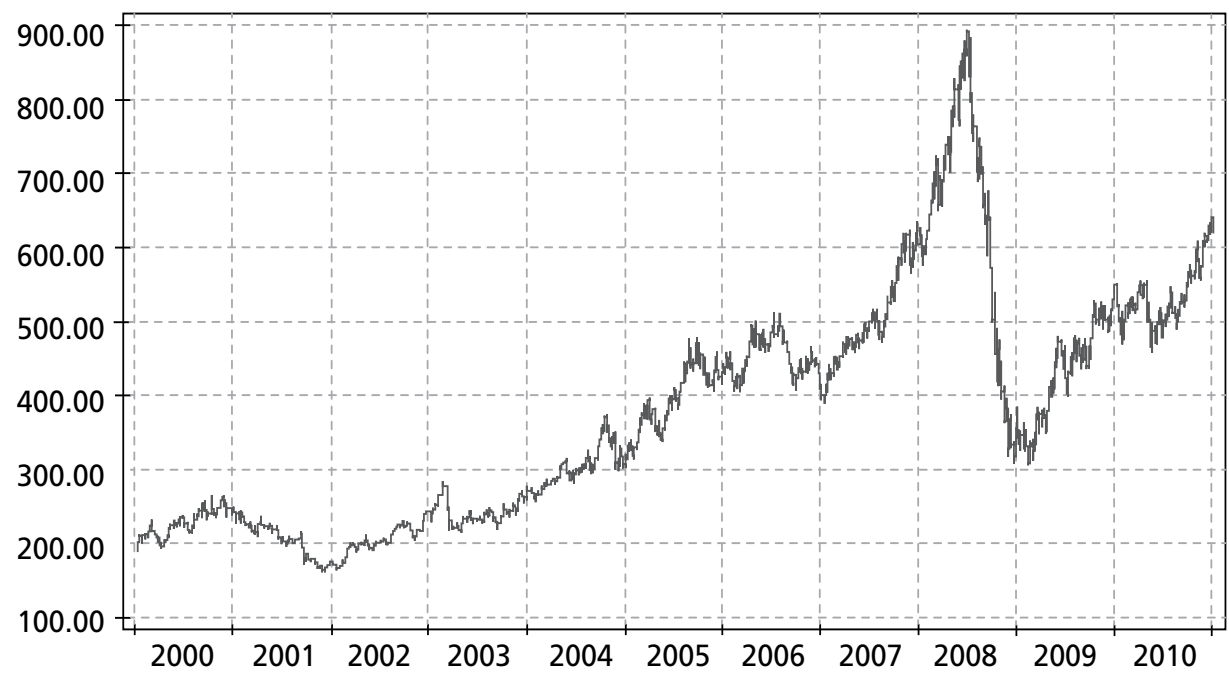

Fuente: Elaboración propia con base en información de Goldman Sachs. 
Gráfica 6. Relación activos/capital contable (número de veces) de un grupo de bancos de inversión, enero 2000-marzo de 2009

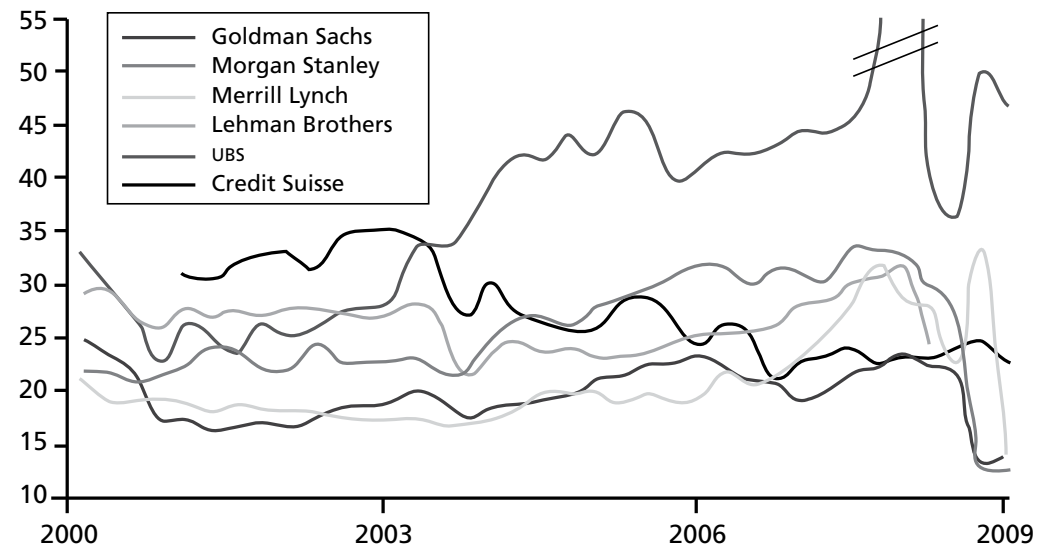

Fuente: Elaboración propia con base en cifras de Bloomberg

Todo lo anterior, propiciado por la menor regulación financiera a partir del inicio del siglo XXI, también se vio influenciado por la relajación de las políticas fiscal y monetaria del gobierno de EU. De ahí el auge de la intermediación y las utilidades involucradas, como ya se ha comentado, y el incremento de los déficit, lo mismo en cuenta corriente (gráfica 7a) que fiscal (gráfica 7b) de dicho país, hasta llegar el primero, a principios de 2006, a $6.5 \%$ del PNB, y el segundo a $4 \%$, a mediados de 2004 .

\section{Gráfica 7. Los déficit de EU \\ (como porcentaje del PNB)}

a) En cuenta corriente de la balanza de pagos, enero de 2000-marzo de 2009

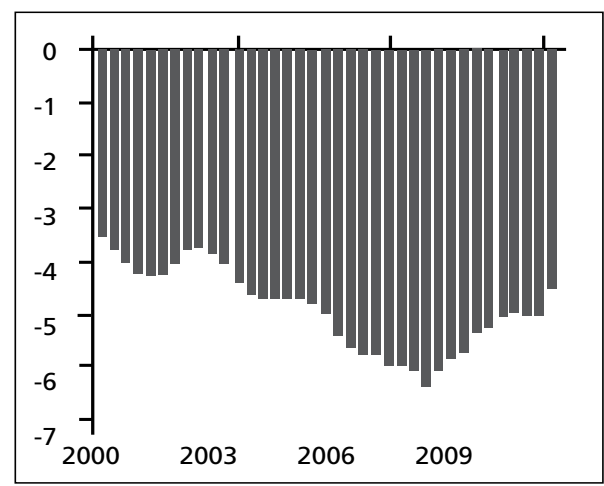

b) Fiscal, enero de 2000-marzo de 2009

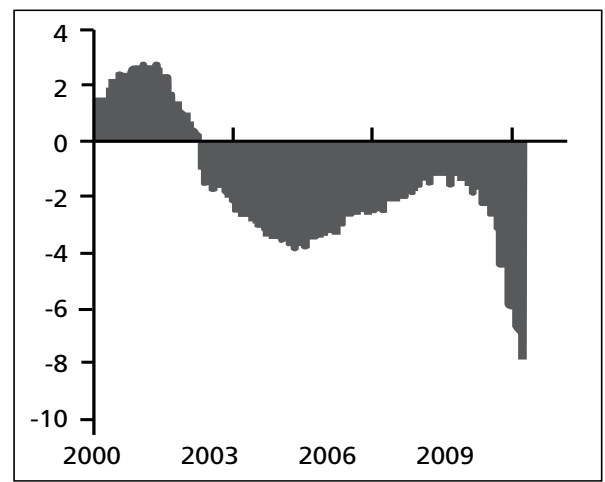

Fuente: Elaboración propia con base en cifras de Bloomberg. 
Dada la identidad macroeconómica que establece que la diferencia entre el ahorro y la inversión de la economía es igual al déficit en la cuenta corriente de la balanza de pagos, la inferencia de la gráfica 7 a es que, a partir de 2000, entre $4 \%$ y $6 \%$ del PNB de EU se financió con recursos externos. Por su parte, la gráfica $7 \mathrm{~b}$ refleja que una porción creciente de gastos del gobierno federal se financió con deuda a partir de 2002, fundamentalmente bonos del Tesoro, absorbiendo con ello no sólo una porción importante del ahorro estadounidense, sino también del superávit (ahorro) de países como China, Japón, Brasil, Arabia Saudita y otras naciones petroleras.

\section{La precipitación de la crisis}

Frente a los problemas descritos, el razonamiento de los financieros era que, gracias a la diversificación del riesgo, el sistema no corría peligro. Entre más se siguieran expandiendo los mercados financieros, más se beneficiaría todo mundo, aunque una gran parte de esos beneficios fluiría necesariamente a las instituciones financieras y se traduciría en altos salarios, regalías y bonos de actuación tanto para los funcionarios de mayor nivel como para los corredores, todos recompensados en razón directa al volumen de sus ventas. Y si a pesar de todo aumentaba el número de hipotecas incobrables, a los clientes morosos que se declararan en quiebra simplemente les quitarían la vivienda objeto del crédito, la venderían y recuperarían su inversión. Algunos llegaban al extremo de decir que, aun sin ser un mercado regulado, en caso de una debacle tanto la Fed como la Federal Deposit Insurance Corporation (FDIC) los rescatarían, como lo habían hecho en el pasado en condiciones similares.

Voces más prudentes, empero, no descartaban la posibilidad de una crisis de dimensiones importantes. Particularmente notoria fue la opinión de Nouriel Roubini, presidente de Roubini Global Economics, quien desde principios del siglo observó la formación de una burbuja en el mercado inmobiliario. En junio de 2007 ratificó sus apreciaciones a través de la National Association of Realtors de EU al manifestar que en ese año se iniciaría una recesión de la economía estadounidense debido a que se volvería persistente la contracción de los precios de las casas habitación. Esto, dijo, llevaría a EU a enfrentar una crisis más profunda que la padecida en 2001-2002 (Roubini, 2007).

Las correas de transmisión de la crisis funcionaron como sigue. Al aumentar la morosidad de la cartera hipotecaria, en 2006, se hizo evidente que la mayor parte de ésta provenía de los créditos subprime. En ellos, el índice de mo- 
rosidad pasó de 12, a principios de ese año, a 25 en 2009, como muestra la gráfica 8, afectando tanto a los bancos comerciales como a los de inversión. En este contexto, los que hasta entonces habían sido considerados los derivados más redituables, los CDS, se volvieron indeseables.

Gráfica 8. Índice de morosidad de la cartera hipotecaria como porcentaje de los créditos totales, enero de 2006-marzo de 2009

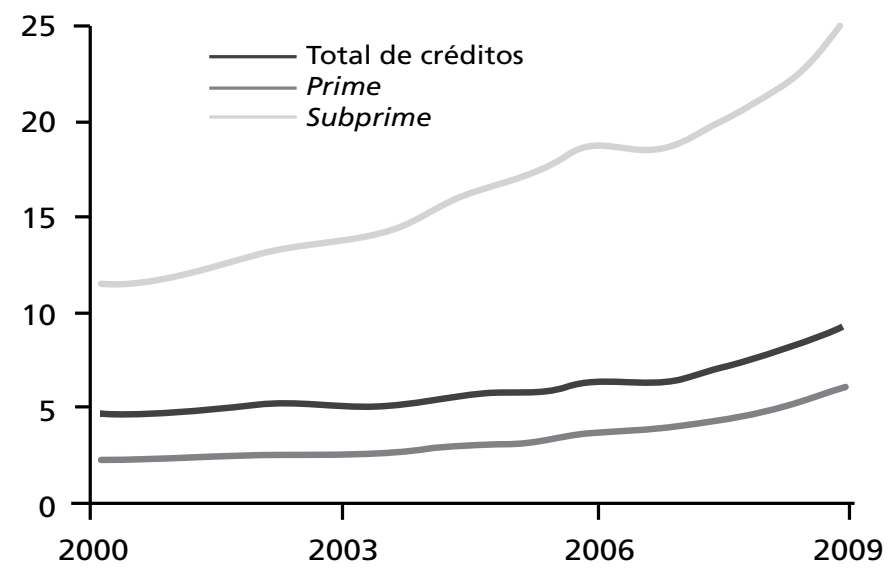

Fuente: Elaboración propia con base en cifras de Bloomberg.

Y aunque los propietarios de las casas hubieran intentado venderlas para pagar su hipoteca, ya no era posible pues valían menos que ésta: su precio acusó una gran caída a partir de 2007, como se observa en la gráfica 9; es decir, los acreditados habían quedado underwater (bajo el agua), de acuerdo con la terminología financiera de EU.

La contracción del índice de precios de los títulos respaldados con hipotecas se extendió desde enero de 2007 hasta entrado 2009, siendo más pronunciada en los títulos de mayor riesgo, los BвB (gráfica 10), con los que habría más deudas hipotecarias de tipo subprime.

De igual manera, se colapsaron los precios de las acciones de los bancos comerciales, como muestra el índice de precios de las acciones de bancos estadounidenses que a partir de 100 en enero de 2007 bajó a entre 5 y 40 en marzo de 2009 (gráfica 11). Esto llevó a la mayoría de dichas instituciones a inscribirse en el programa de rescate emprendido por el gobierno, y orilló a algunas a ser absorbidos por otras más grandes, como sucedió con el banco Wachovia. 
Gráfica 9. Precio promedio real y nominal de casas nuevas, con sus respectivas tendencias precrisis, 1970-2010

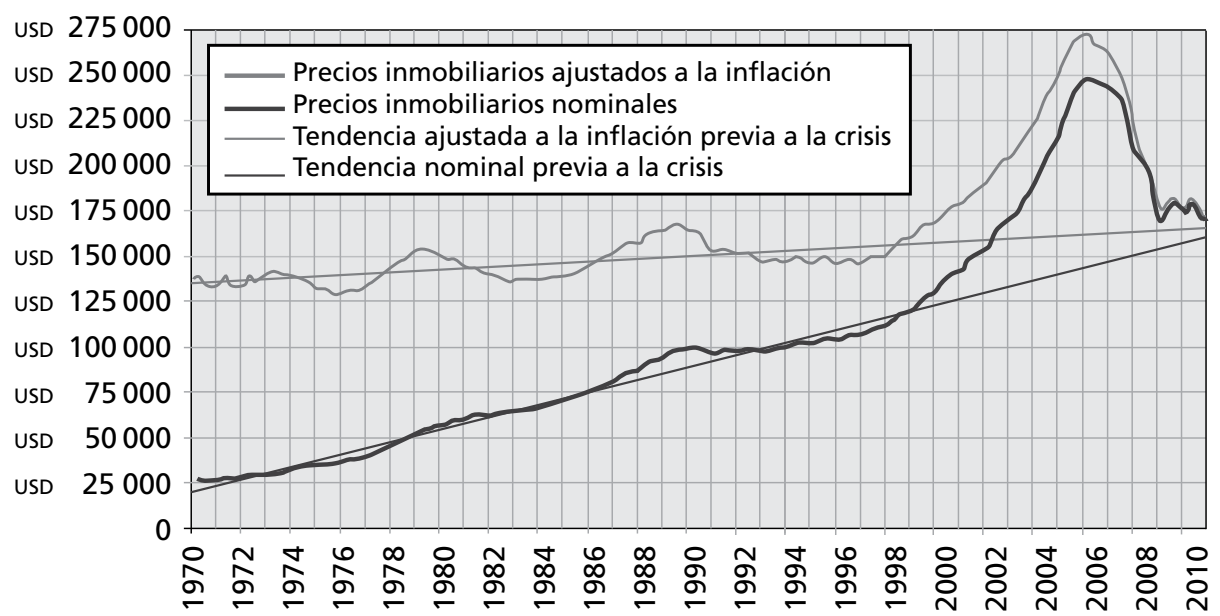

Fuente: Elaboración propia con base en información de Parsons (s.f.).

Gráfica 10. Índices de precios de títulos respaldados por hipotecas, enero de 2007-abril de 2009

(base enero de $2007=100$ )*

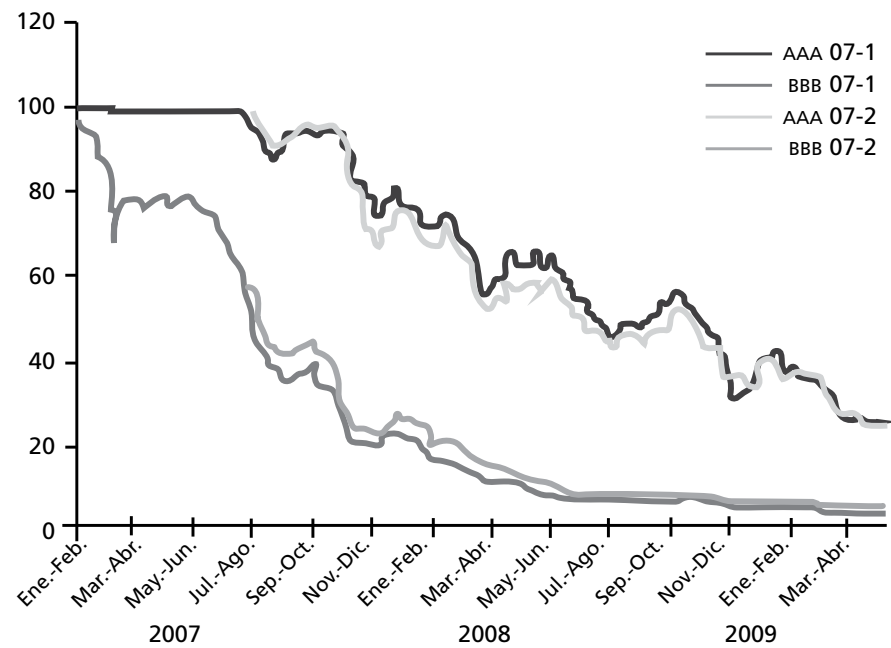

* Obtenidos de índices de derivados de incumplimiento crediticio.

Fuente: Elaboración propia con base en información de Credit Suisse. 
164 ECONOMÍA: TEORÍA Y PRÁCTICA • Nueva Época, número 39, julio-diciembre 2013

\section{Gráfica 11. Precios de acciones de bancos estadounidenses,} enero de 2007-junio de 2009

(base enero de $2007=100$ )

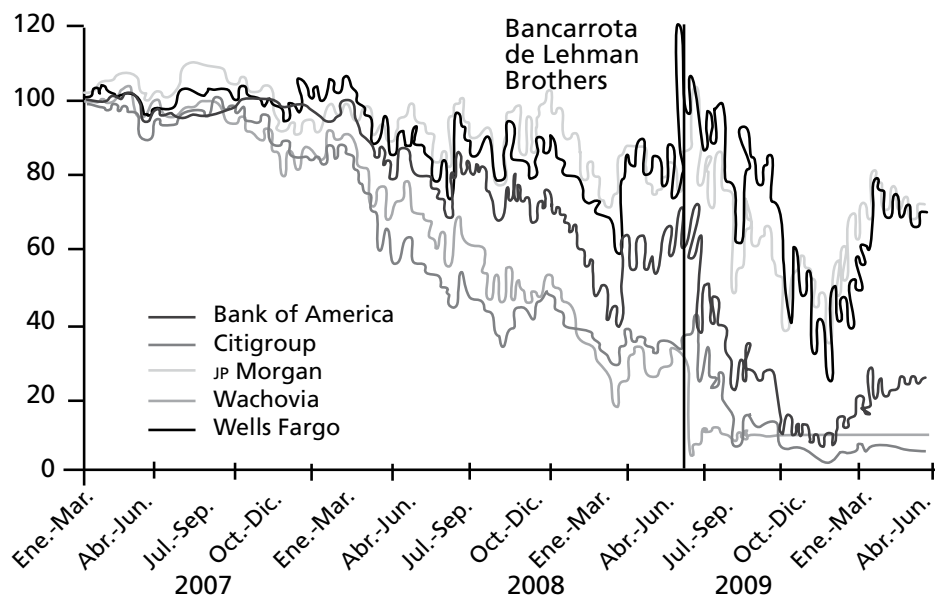

Fuente: Elaboración propia con base en cifras de Bloomberg.

Gráfica 12. Actividad de titularización en EU (billones de dólares)

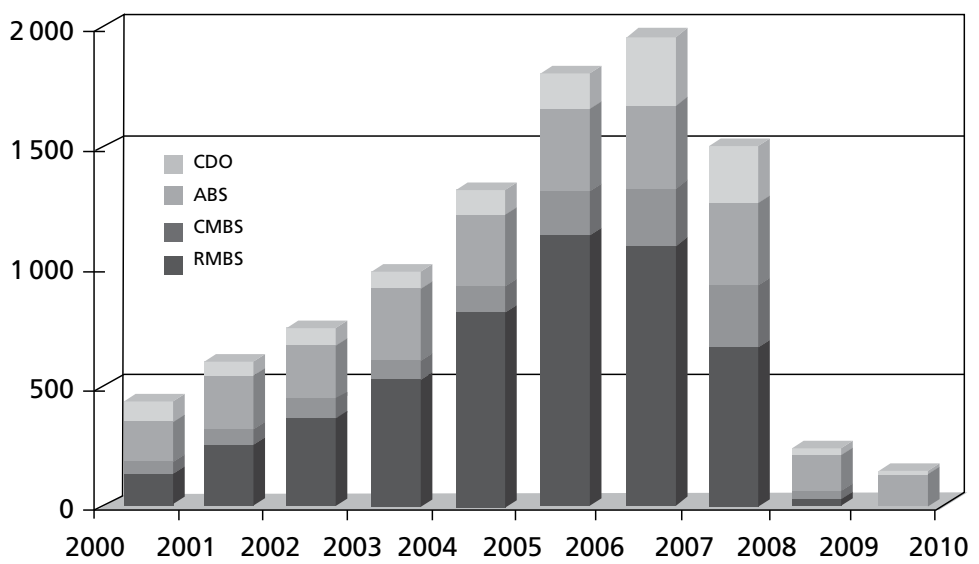

Nota: CDO: obligaciones de deuda colateralizadas (collateralizaed debt obligations). ABS: valores respaldados por bienes (asset backed securities). CMBS: valores respaldados por hipotecas comerciales (commercial mortage-backed securities). RMBS: valores respaldados por hipotecas residenciales (residential mortage-backed securities)

Fuente: Elaboración propia con base en Thomson Reuters. 
Ante las condiciones descritas, se derrumbó la titularización de activos a partir de 2007 al bajar de casi dos billones de dólares, en 2006, a menos de 250 000 millones de dólares en 2008 (gráfica 12). Con esto se dejaron de titularizar los MBS tanto de tipo residencial como comercial, que eran los instrumentos de mayor toxicidad. Lo mismo pasó con las CDO al tiempo que se reducían mucho los valores respaldados por activos (ABS, por asset backed securities).

La desconfianza causada por los problemas descritos condujo a una gran astringencia monetaria. Como muestra la gráfica 13, las variaciones mensuales del principal indicador de la oferta monetaria, el M3, descendieron agudamente a partir de enero de 2008, hasta tocar fondo a mediados de 2010 .

\section{Gráfica 13. Oferta monetaria por desagregados (variaciones mensuales en porcentaje)}

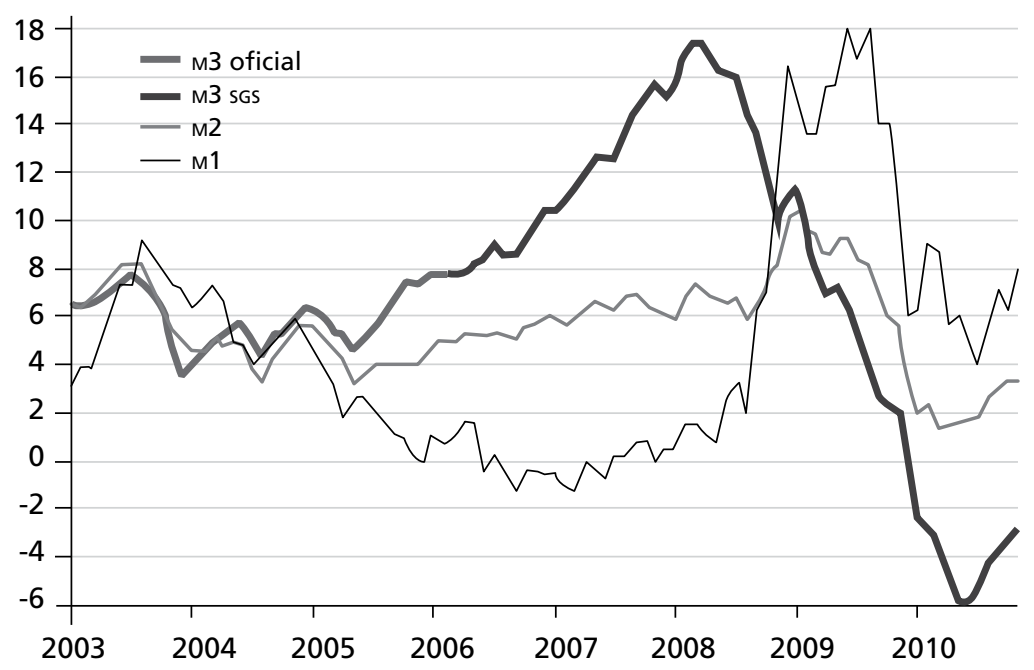

Fuente: Elaboración propia con base en Shadowstats.

A partir de lo anterior sobrevino, en el mismo 2008, una crisis de crédito (credit crunch). Los bancos restringieron los préstamos en toda su gama de instrumentos, siendo los más afectados los de tipo hipotecario, particularmente los subprime, como se aprecia en la gráfica 14. En seguida se ubicaron, en términos de afectación, otros créditos al consumo, créditos para la compra de bienes raíces comerciales y tarjetas de crédito. 


\section{Gráfica 14. Variaciones anuales del crédito bancario en EU por destino, enero de 2004-junio de 2009 \\ (porcentaje)}

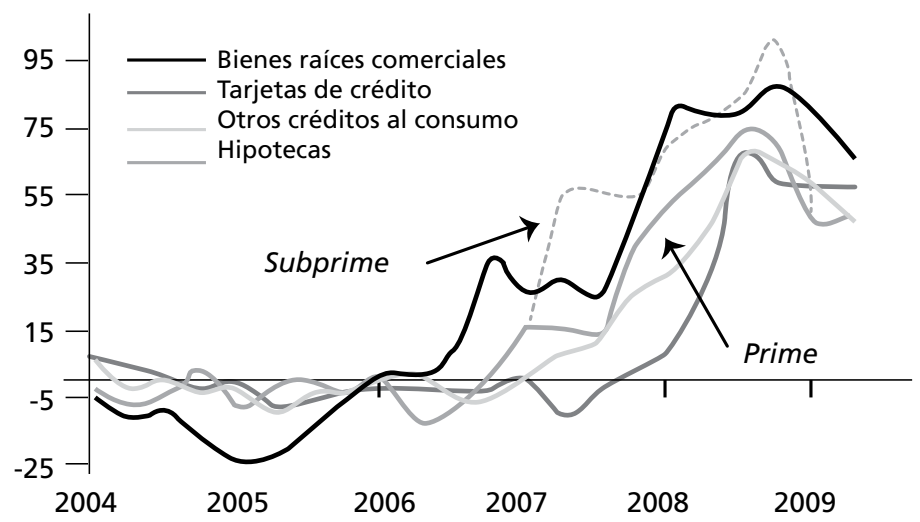

Fuente: Fed (s.f.).

La contracción señalada afectó al crédito no financiero lo mismo de EU que de todos los países desarrollados, aunque debe resaltarse que el descenso se había iniciado en 2005, alcanzando su peor nivel a mediados de 2009. Después de EU, el país más afectado fue Reino Unido. Los países de la zona euro, que habían capeado el problema hasta entrado 2008, finalmente también sucumbieron, como muestra la gráfica 15 , corroborando su involucramiento en las hipotecas titularizadas de origen estadounidense.

Como en la mayoría de los estallidos de burbujas financieras generadoras de grandes fortunas, hubo señales de que una crisis se aproximaba. La primera fue el anuncio de descapitalización del banco de inversión Bear Stearns, a partir de marzo de 2008, que no se convirtió en quiebra gracias a que el gobierno de EU apoyó su absorción por parte de JP Morgan Chase. No hizo lo mismo con otro de los cinco mayores bancos de inversión del país, Lehman Brothers, al cual dejó desaparecer una vez decretada su quiebra, en septiembre del mismo año. ${ }^{11}$ Esto condujo a los mercados a un pánico del que el antecedente más memorable era la contracción bursátil de octubre de 1929, inicio de la Gran Depresión (Galbraith, 1976).

${ }^{11}$ Un testimonio de enorme valía sobre los detalles de la quiebra de Lehman Brothers, vista desde adentro, es el de Felipe Coello (2011), mexicano que trabajó para dicho banco durante sus últimos diez años. 
Gráfica 15. Crecimiento anual real de los préstamos bancarios no financieros en países desarrollados, 2004-2010 (porcentaje)

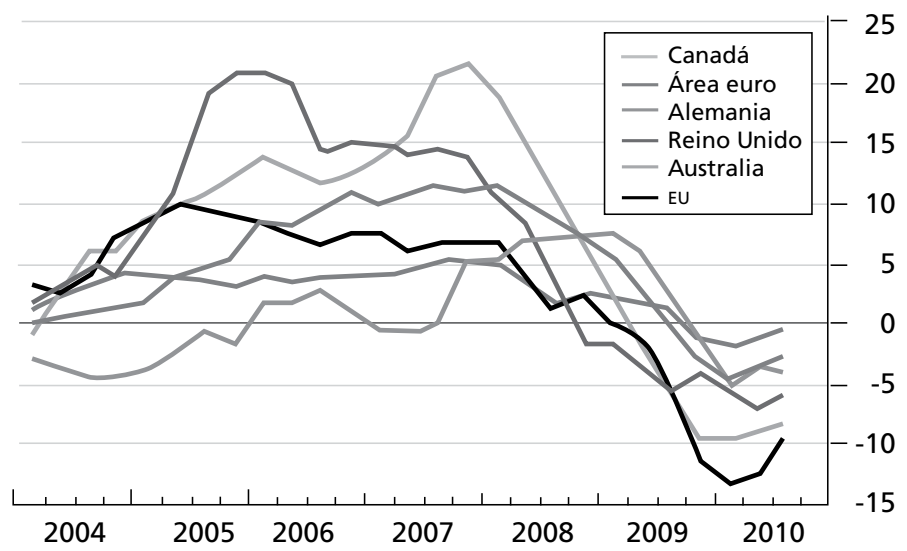

Fuente: Barclays Capital.

Cuando la crisis se hizo evidente en los mercados financieros, las instituciones bancarias que lograron despojarse de sus CDO enfrentaron enormes pérdidas. Las agencias calificadoras, seriamente criticadas por haber otorgado niveles AAA a los documentos, les redujeron la calificación, con lo que exacerbaron el problema y expandieron la crisis por todos los segmentos del mercado, ya que los bancos las habían comprado, en la mayoría de los casos, con fondos prestados y se vieron obligados a deshacerse de activos más seguros, los únicos que el mercado estaba dispuesto a aceptar. Debido a que las deudas hipotecarias y de otro tipo se encontraban titularizadas y los paquetes adquiridos mezclaban títulos sanos con tóxicos, ninguna institución conocía a ciencia cierta el valor de los títulos que tenía en su poder. Y dado que los bancos están obligados a dar a sus títulos el valor que determine el mercado, el capital bancario se evaporó junto con el precio de éstos.

El problema se exacerbó porque las instituciones financieras de última instancia, que habían otorgado préstamos a los bancos durante los meses previos al colapso de Lehman Brothers a un ritmo más acelerado del que podían recuperarlos, dejaron de hacerlo. Esto los obligó a cerrar la brecha crediticia con préstamos de corto plazo, generalmente de tipo interbancario, los cuales después del colapso fue imposible refinanciar. Esta descapitalización provocó que los bancos restringieran, primero, su flujo de crédito a inversionistas no bancarios $\mathrm{y}$, después, a sus pares. Con ello, la crisis se hizo aún más grande y las instituciones 
reguladoras se atemorizaron, contagiando a la National Futures Association (NFA), encargada de salvaguardar la integridad de los mercados a futuro. Los estudios sobre crisis financieras muestran que el riesgo es siempre subestimado en periodos de auge y sobredimensionado durante las crisis e inmediatamente después del pico de éstas. En este entorno, se pusieron al descubierto los fraudes de algunos fondos de inversión basados en el esquema piramidal de Ponzi, como el Maddof y el Stanford, lo que exacerbó la desconfianza en el sistema financiero. El primero era administrado por un respetable financiero, otrora presidente del índice de acciones tecnológicas Nasdaq. ${ }^{12}$ La pérdida de confianza y la falta de crédito impactaron al consumo personal, el cual -luego de una tendencia ascendente por lo menos desde la conclusión, en 2002, de la crisis de la burbuja tecnológica- empezó a declinar a partir de enero de 2008 y se mantuvo en números negativos hasta mayo de 2009. Cuatro meses después sufrió una fuerte recaída, de la que rápidamente se recuperó (gráfica 16). Como consecuencia, la participación de esta variable en el PNB, que había mostrado un ascenso continuo a partir de la posguerra, se estancó en $71 \%$ durante la recesión.

Una economía como la estadounidense, en la que el peso del consumo y el adecuado funcionamiento de los mercados financieros son fundamentales,

Gráfica 16. Variación trimestral del consumo personal real en eu, 2007-2010 (porcentaje)

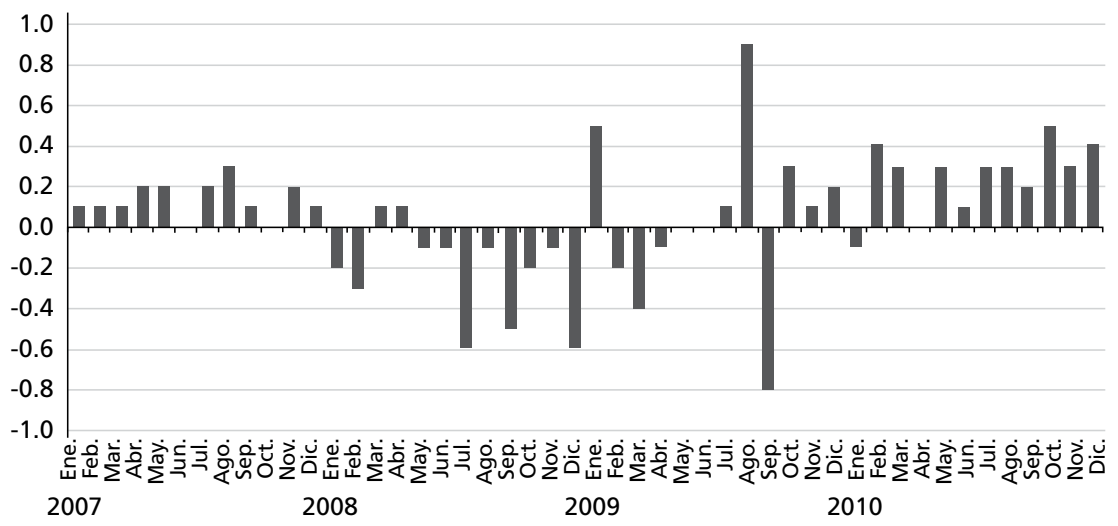

Fuente: BEA (s.f.b).

${ }^{12}$ El fraude del fondo Maddof llegó a 60000 millones de dólares y llevó a su arquitecto a prisión, donde purga una sentencia de 110 años. Durante la crisis de 2001-2002 también se descubrieron fraudes por ocultación de información que afectaron la credibilidad del sistema; se les conoció como "contabilidad creativa" y quedaron envueltas enormes empresas, entre ellas Enron, WorldCom, Arthur Andersen, Xerox, Citigroup, AT\&T, America-on-Line y General Motors (Gutiérrez, 2004). 
tiende a contraerse severamente cuando la primera variable desciende y hay desconfianza en el futuro de la segunda. Así, el PNB sufrió, a partir del primer trimestre de 2008, una caída que duró 18 meses (gráfica 17), de acuerdo con el reporte final al respecto elaborado por la institución privada que cuantifica los ciclos económicos, el National Bureau of Economic Research (NBER, 2010), duración que no se observaba para una recesión desde la segunda Guerra Mundial.

\section{Gráfica 17. Variación trimestral del PNB de EU y promedio móvil, enero de 2001-diciembre de 2010 \\ (porcentaje)}

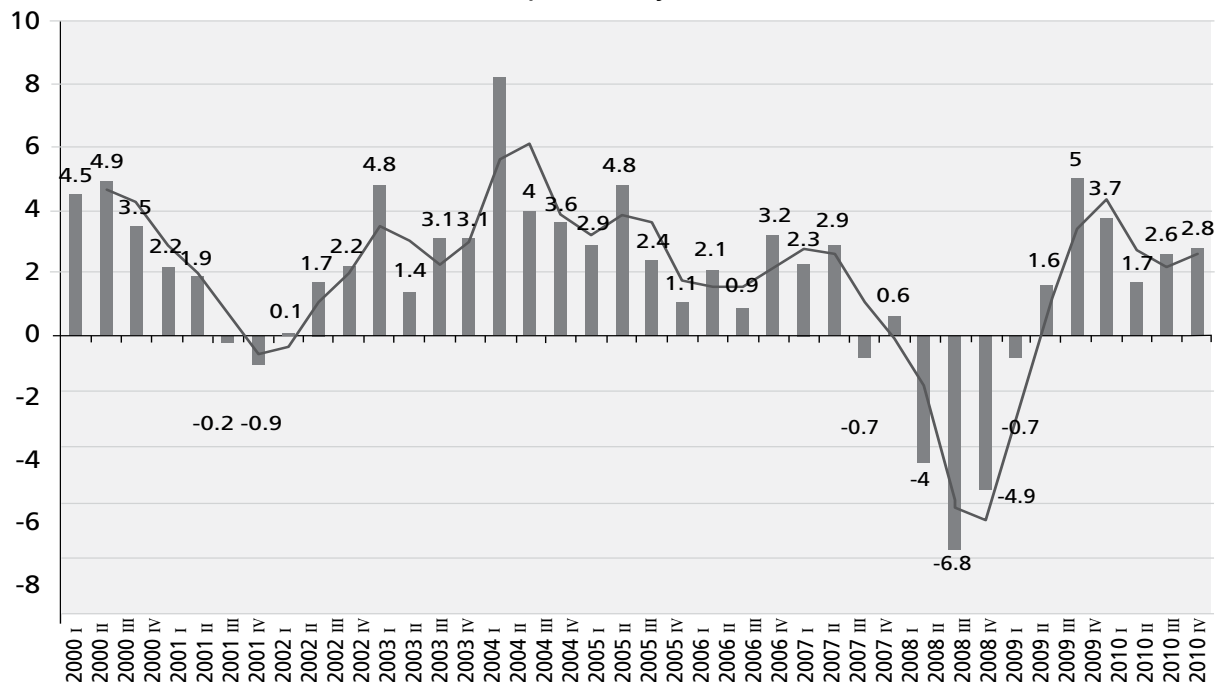

Fuente: Elaboración propia con base en datos de BEA (s.f.a)

De haberse tomado en cuenta las llamadas de atención de diversos observadores, como Pérez (2004), por ejemplo, respecto al peligro de los movimientos de capital desde los años noventa y del sobrecalentamiento y relajación del sistema financiero, un poco después, se podrían haber revertido a tiempo las tendencias desfavorables del mercado en 2007 y seguramente las consecuencias de la crisis habrían sido mucho menores, así como los recursos erogados para paliarla. ${ }^{13}$ Por el contrario, en varias instancias el problema desbordó a las autori-

\footnotetext{
${ }^{13}$ El mismo Congreso de EU, en un documento histórico de evaluación de la crisis (Financial Crisis Inquiry Commission, 2011), aunque sin contar con el apoyo de la mayoría del ala republicana, reconoció los aspectos negativos de la desregulación financiera y el hecho de que, con las medidas adecuadas, dicha crisis pudo haberse evitado.
} 
dades de EU, con rescates financieros estratosféricos, que se estarán pagando a lo largo de muchos años y que son causa de cambios severos en los ejes del poder económico y político mundial: China subió en 2009 al segundo lugar en términos de producción y al primero en términos de exportaciones (UNCTAD, 2010). ${ }^{14}$

\section{EL RESCATE}

A partir del cuarto trimestre de 2008, el gobierno de eu puso en operación, mediante la coordinación conjunta del Departamento del Tesoro y la Fed, un programa de rescate (bailout) cuyo propósito principal era evitar el desencadenamiento de una crisis sistémica. ${ }^{15}$ Éste consistió, en primera instancia, en la expansión de la política fiscal mediante la aportación de recursos sin precedentes a las entidades del sector financiero -y algunas del sector real- así como la reducción de impuestos a los consumidores y a estratos especiales de los productores. A esas alturas se estimaba que la necesidad total de recursos para paliar la crisis sería de dos billones de dólares, equivalentes a 14\% del PNB estadounidense en aquel momento y, por supuesto, se sabía que cerca de dos terceras partes

${ }^{14}$ Cabe recordar algunas afirmaciones que en 2010 hizo Paul Volcker -jefe entre 1979 y 1987 del Board of Governors of the Federal Reserve System de Eu y director del Economic Recovery Advisory Board de Barak Obama hasta 2010 - durante una entrevista con el exgobernador del Banco de México, Guillermo Ortiz: "La idea de los expertos financieros era que la titularización y retitularización de activos al diversificar el riesgo en realidad lo reducía; pero al final no fue así: entre $20 \%$ y $30 \%$ de los acreedores de hipotecas de eu quedaron en una situación en que valía más la deuda hipotecaria que la propiedad (underwater) [...] Para la resolución de los problemas de deuda de Eu el gobierno deberá, en el curso de los siguientes años, aumentar sus exportaciones en el equivalente a cuatro puntos porcentuales de su PNB y, al mismo tiempo, reducir el saldo de su endeudamiento, incluyendo el de tipo hipotecario... Los derivados más conocidos y letales para esta crisis han sido los credit default swaps, que involucraron transacciones por más de 60 millones de millones de dólares y se cobraron a precios muy altos debido a su opacidad [...] De la misma manera, tanto los fondos de protección como los equity funds son dignos de atención por su gran volumen y peligrosidad [...] Los bancos saben que en casos extremos el gobierno los rescata. Hay que parar eso: si un banco llega a quebrar, que con él se vayan sus accionistas y acreedores, y punto" (Volcker, 2010).

${ }^{15}$ Ante lo costoso del rescate y la creencia de que los mercados financieros ya habían absorbido, en general, el efecto de la crisis financiera, el gobierno de George Bush se mostró omiso cuando, en septiembre de 2008, el quinto banco de inversión del país, Lehman Brothers, anunció que se encontraba descapitalizado y, sin intentar rescatarlo, lo dejó quebrar. Los cálculos de esta decisión fueron erróneos y sus consecuencias dramáticas: a partir de ese momento sobrevino un verdadero desplome de los mercados y una auténtica internacionalización de la crisis. El gobierno corrigió reforzando el programa de rescate y no sólo no lo concluyó al terminar su mandato, en enero de 2009, sino que dejó acciones pendientes al de Barak Obama. 
las absorbería el sector financiero. Para poner en operación dicho rescate, el Congreso aprobó la Emergency Economic Stabilization Act of 2008, la cual entró en operación el 3 de octubre de ese año, aunque ya antes se habían asignado recursos al sector financiero de manera aislada, como se muestra a continuación para el caso de las principales instituciones beneficiadas:

- JP Morgan Chase y el gobierno federal rescataron a Bear Stearns, cuyos problemas empezaron en marzo de 2008 y que fue comprado por 236000 millones de dólares, con ayuda de un crédito gubernamental de 30000 millones a JP Morgan Chase para asegurar la venta, ante la perspectiva de que se derrumbaran los mercados.

- En septiembre de ese mismo año, Fannie Mae y Freddie Mac virtualmente se estatizaron, ya que quedaron al cuidado de la Federal Housing Finance Agency. Inicialmente se asignaron 100000 millones de dólares de inversión a cada entidad y en febrero de 2009 se les duplicó el monto, con base en la Housing and Economic Recovery Act of 2008, que había sido puesta en operación en julio de ese año. Así, se llegó a un total de 400000 millones de rescate, la mitad por institución.

- En cuatro ocasiones, el gobierno ofreció a la aseguradora más grande del mundo, el American Investment Group (AIG) su apoyo para no colapsarse, pasando de 85000 millones de dólares iniciales de la Fed hasta un esfuerzo combinado de 180000 millones por parte de éste (110000 millones) y el Departamento del Tesoro (70000 millones), y un compromiso adicional del segundo de 40000 millones, con lo que se haría un total de 220000 millones de dólares. ${ }^{16}$

- Citigroup, el banco más grande del mundo, recibió 25000 millones de dólares en octubre y otros 20000 millones en noviembre. Además, fue objeto de apoyo gubernamental a través de garantías para limitar las pérdidas de sus activos tóxicos, calculados en 301000 millones. Asimismo, el Departamento del Tesoro comprometió recursos por 5000 millones de dólares, más 10000 millones de la FDIC y 220000 millones de la Fed. La suma de recursos ascendió a 280000 millones. Aun con estos problemas, en septiembre intentó absorber a Wachovia, cuarto banco en tamaño de EU, el cual finalmente se fusionó con Wells Fargo en una operación que

\footnotetext{
${ }^{16}$ AIG fue responsable de la emisión de muchos instrumentos de aseguramiento sofisticados y finalmente castigados por el mercado, como los Regulatory-capital-enhancement swaps.
} 
costó a éste 14800 millones de dólares y de la que surgió el banco más diversificado del país.

- El Bank of America obtuvo 45000 millones de dólares, incluyendo 10000 millones destinados a comprar Merrill Lynch. ${ }^{17}$ Adicionalmente, integró garantías para limitar la pérdida de 118000 millones de activos en problemas. También, el Departamento del Tesoro comprometió 7500 millones de dólares; la FDIC, 2500 millones, y la Fed, hasta 87200 millones, para un total de 142200 millones. $^{18}$

La determinación del monto de recursos necesarios para el rescate posterior a la sorpresa de la segunda mitad de 2008 incluyó una serie de estudios entre los que se contaron severas pruebas de estrés, practicadas institución por institución. En los casos requeridos, el gobierno tomó control temporal del consejo de administración de las instituciones y aclaró que, una vez superada la contingencia, todas deberían devolver los recursos recibidos. Además, se informó que el Ejecutivo promulgaría una ley para habilitar a la Fed y al Departamento del Tesoro a ejercer un mayor control sobre el sistema financiero en su conjunto, con especial referencia a las operaciones no reguladas, lo que se materializó con la aprobación del Congreso, en julio de 2010, de una reforma financiera de carácter regulatorio, la The Wall Street and Consumer Protection Act, que generó una gran controversia, por ser la primera después de muchos años en que se fijaban límites a la expansión del sector financiero.

Si se toman en cuenta no sólo los recursos públicos comprometidos por la vía de apoyos directos del gobierno estadounidense al sistema financiero -que, de acuerdo con el cuadro 3, representan 7.4\% del PNB-, sino las garantías ofrecidas, que ascienden a $7.5 \%$ del PNB, se llega a un total de apoyos equivalente a $14.9 \%$, ligeramente superior al cálculo original del costo del rescate (14\%). Evi-

\footnotetext{
${ }^{17}$ Como otras absorciones, la compra de Merrill Lynch por parte del Bank of America fue objeto de severas controversias. Por ejemplo, a principios de 2010, dicho banco, junto con dos ejecutivos de alto nivel, fue acusado por el fiscal general de Nueva York de cometer fraude en un proceso de titularización en que no se tomaron en cuenta las pérdidas en que incurrirían los tenedores de acciones; sólo querían que aprobaran la absorción de Merrill Lynch en 2009. Esto provocó que, con base en la experiencia de conflictos similares, la Securities and Exchange Commission (SEC) impusiera al banco una multa por 150 millones de dólares, que se repartirían entre los tenedores de las acciones para resarcirlos de sus pérdidas, quedando todo sujeto a la aprobación del juez de una corte federal.

${ }^{18}$ En total, a mediados de 2010 más de 670 entidades financieras estadounidenses (y cincuenta europeas) habían recibido recursos públicos vinculados al rescate (Iglesias-Sarría y Vargas, 2010)
} 
dentemente, la cifra crece cuando se agregan el intercambio y compra de activos, es decir, la adquisición de deuda gubernamental por parte de los bancos centrales, ya que representa $12.1 \%$ del PNB, con lo que se alcanza un total de recursos comprometidos de $27 \%$. Debe destacarse que el país más afectado de los siete listados no es EU, sino Reino Unido, cuya suma de recursos comprometidos más garantías asciende a $51.9 \%$ de su PNB, y se amplía a $80.1 \%$ al considerar el intercambio y compra de activos.

Cuadro 3. Recursos públicos utilizados para apoyar al sistema financiero en las siete mayores economías de la OCDE

(porcentaje del PNB)

\begin{tabular}{|c|c|c|c|c|c|c|c|}
\hline \multicolumn{5}{|c|}{ Recursos en apoyos directos* } & \multicolumn{3}{|c|}{ Apoyos directos } \\
\hline País & Comprometidos & Utilizados & Recuperados & $\begin{array}{l}\text { Costo } \\
\text { neto }\end{array}$ & Garantías & $\begin{array}{l}\text { Intercambio } \\
\text { y compra de } \\
\text { activos** }\end{array}$ & $\begin{array}{l}\text { Total de recursos } \\
\text { comprometidos }\end{array}$ \\
\hline & A & B & c & $D=B-C$ & $\mathrm{E}$ & $\mathrm{F}$ & $G=A+E+F$ \\
\hline $\begin{array}{l}\text { Economías } \\
\text { avanzadas }\end{array}$ & 6.2 & 3.5 & 0.8 & 2.7 & 10.9 & 7.7 & 24.8 \\
\hline Canadá & 9.1 & 4.4 & 0.0 & 4.4 & 0.0 & 0.0 & 9.1 \\
\hline Francia & 1.5 & 1.1 & 0.8 & 0.3 & 16.9 & 0.0 & 18.4 \\
\hline Alemania & 3.4 & 4.9 & 0.0 & 4.8 & 17.2 & 0.0 & 20.6 \\
\hline Italia & 1.3 & 0.3 & 0.0 & 0.3 & 0.0 & 2.7 & 4.0 \\
\hline Japón & 6.5 & 0.1 & 0.0 & 0.1 & 7.2 & 0.0 & 13.8 \\
\hline $\begin{array}{l}\text { Reino } \\
\text { Unido }\end{array}$ & 11.9 & 6.6 & 1.1 & 5.4 & 40.0 & 28.2 & 80.1 \\
\hline $\begin{array}{l}\text { Estados } \\
\text { Unidos }\end{array}$ & 7.4 & 4.9 & 1.3 & 3.6 & 7.5 & 12.1 & 27.0 \\
\hline
\end{tabular}

* Aportaciones de capital, compra de activos y préstamos.

** Incluye compra de deuda gubernamental por parte de los bancos centrales. Fuente: IMF Fiscal Monitor (2010, pp. 10-23).

Como promedio global, el Fondo Monetario Internacional (IMF Fiscal Monitor, 2010) estimó que el monto total de recursos públicos comprometidos para apoyar al sistema financiero podría llegar a $24.8 \%$ del PNB de los países avanzados -con una gran variabilidad entre sus valores promedio-, y a $0.8 \%$ del de los emergentes. La cifra de los primeros estaba integrada por lo siguiente: apoyos directos al sector financiero por una cantidad equivalente a $6.2 \%$ del PNB (aportaciones de capital por $3.8 \%$ y compra de activos y préstamos por $2.4 \%$ ); garantías emitidas por un monto equivalente a $10.9 \%$ del PNB, e intercambio 
y compra de activos por parte de los bancos centrales por un equivalente a $7.7 \%$ del PNB. El costo neto estimado de los apoyos directos sería de $2.7 \%$ del PNB, cifra que tendería a disminuir a medida que la economía mundial se recuperara.

Lo paradójico del presupuesto fue que los gobiernos tuvieron que aumentar sus egresos a pesar de que sus ingresos cayeron. De acuerdo con cálculos de la Organización para la Cooperación y el Desarrollo Económicos (OCDE), los ingresos fiscales, como porcentaje del PNB, se redujeron en la mayoría de sus países miembros en 2009 respecto a 2007 (gráfica 18). En promedio, para los treinta miembros hasta ese momento, el coeficiente de impuestos fue de $35.4 \%$ en el primer año y de $33.7 \%$ en el segundo.

Con un coeficiente de $24 \%$, EU fue uno de los países ricos con menor carga impositiva, la cual se redujo 3.9 puntos porcentuales entre 2007 y 2009. Como contrapartida, Dinamarca registró el mayor coeficiente, el cual sólo bajó 0.8 puntos porcentuales entre uno y otro año: de $49.4 \%$ en 2007 a $48.2 \%$ en 2009.

Gráfica 18. Participación de los impuestos en el PNB de países seleccionados de la OCDE (2009) y sacrificio fiscal debido a la crisis (2007-2009)

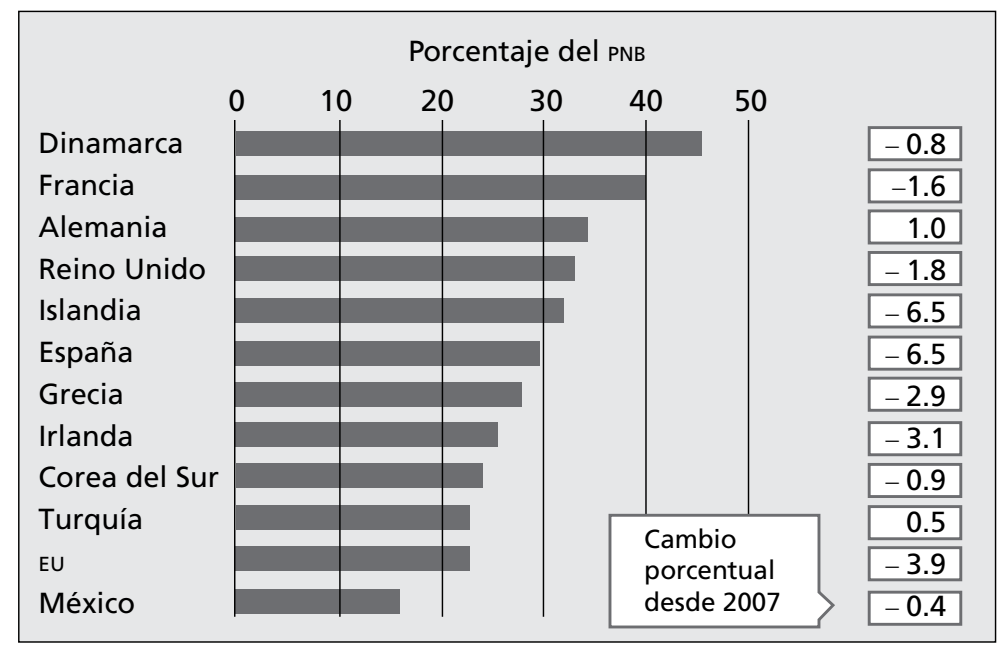

Fuente: Elaboración propia con base en OCDE (s.f.).

Lo anterior tuvo enormes costos para la economía estadounidense y el resto de países cuyos sistemas financieros se involucraron en el negocio de los fondos de protección y derivados. Como muestra el cuadro 4, los diez países listados exhibían en 2009 altos niveles de déficit gubernamental, particularmen- 
te EU (con 8\% del PNB) y Reino Unido (con 7.9\%); sólo Alemania e Italia se ubicaban cerca del tope establecido por el Tratado de Masstricht, de 3\%. En cuanto a la deuda gubernamental neta, Grecia, Italia y Japón exhibieron los niveles más abultados: entre $99 \%$ del primer país y $121 \%$ del tercero. Asimismo, el déficit en cuenta corriente de la balanza de pagos afectó a todos, excepto a Alemania y Japón.

Cuadro 4. Déficit gubernamental deuda soberana y saldo en la cuenta corriente de países seleccionados de la OCDE al cierre de 2009

(porcentaje del PNB)*

\begin{tabular}{lcccc}
\hline \multicolumn{1}{c}{ País } & $\begin{array}{c}\text { Déficit } \\
\text { gubernamental** }\end{array}$ & $\begin{array}{c}\text { Deuda } \\
\text { gubernamental } \\
\text { bruta }\end{array}$ & $\begin{array}{c}\text { Deuda } \\
\text { gubernamental } \\
\text { neta }\end{array}$ & $\begin{array}{c}\text { Balanza de } \\
\text { cuenta corriente }\end{array}$ \\
\hline Francia & 5.0 & 84.2 & 74.5 & -1.8 \\
Alemania & 3.1 & 75.3 & 56.7 & 6.1 \\
Grecia & 7.4 & 130.2 & 109.5 & -10.8 \\
Irlanda & 8.6 & 93.6 & 55.2 & -2.7 \\
Italia & 3.6 & 118.4 & 99.0 & -2.9 \\
Japón & 7.6 & 225.9 & 120.7 & 3.1 \\
Portugal & 6.1 & 83.1 & 78.9 & -10.0 \\
España & 7.5 & 63.5 & 54.1 & -5.2 \\
Reino Unido & 7.9 & 76.7 & 68.8 & -2.2 \\
\hline Estados Unidos & 8.0 & 92.7 & 65.8 & -3.2 \\
\hline
\end{tabular}

* Con base en las proyecciones más recientes estimadas para 2010

** Balance fiscal ajustado para los efectos del ciclo económico y para elementos no estructurales. Estos últimos incluyen movimientos temporales en el sector financiero y en el precio de los activos, así como conceptos de ingresos o gastos que aparecen una sola vez o temporalmente.

Fuente: IMF (2010).

Por lo que se refiere al sector real de la economía estadounidense, los recursos más cuantiosos se asignaron a la industria automotriz. Como primer paso, recibió un préstamo por 25000 millones de dólares a tasas preferenciales, con el fin de afrontar las pérdidas derivadas de la contracción del mercado. Paralelamente, se solicitó a sus empresas impulsar el desarrollo de tecnologías amigables con el medio ambiente. Las inicialmente beneficiadas fueron las tres grandes de Detroit: General Motors, Ford y Chrysler. Posteriormente, en diciembre de ese mismo 2008, se hizo un préstamo a General Motors y Chrysler por 81.3 miles de 
millones de dólares a fin de prevenir su eventual bancarrota. Con esto, el total asignado al sector llegó a 106.3 miles de millones de dólares.

En febrero de 2009, bajo la administración de Barak Obama, el Congreso aprobó la American Recovery and Reinvestment Act of 2009, un paquete de estímulo a la economía por 787000 millones de dólares, de los que más de la mitad se referían a sacrificios fiscales de carácter federal y local (estados y condados) destinados a las empresas y particulares, y el resto a impulsar la infraestructura, la ciencia, la salud, la energía, la educación, la capacitación y la protección a las personas más vulnerables (gráfica 19).

Gráfica 19. Distribución de los 778000 millones de dólares de la American Recovery and Reinvestment Act of 2009

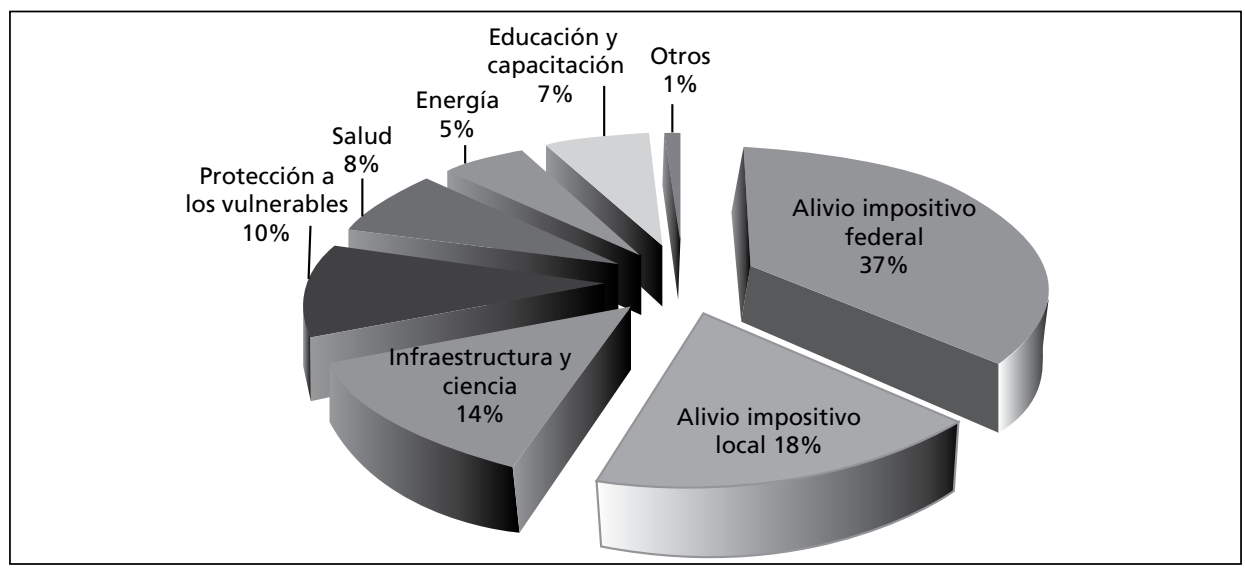

Fuente: Elaboración propia con base en la American Recovery and Reinvestment Act (2009).

Por el lado de la política monetaria, además del mantenimiento de la tasa de fondos federales en $0.25 \%$ a partir de 2008 , situándose en su nivel histórico más bajo (gráfica 20), la Fed acordó adquirir, en un lapso de varios años y mediante operaciones de mercado abierto, 600000 millones de dólares de Bonos del Tesoro, con el fin de aumentar el circulante y estimular la economía. Estas herramientas, conocidas como quantitative easing, enfrentaron serias presiones internacionales y del propio Congreso de EU a partir de 2011. Empero, se reeditó dos veces hasta llegar, en septiembre de 2012, al quantitative easing 3 , vertiente por la que se asignaron 40000 millones de dólares mensuales a la compra, durante varios años, de activos tóxicos MBS, además de mantenerse, hasta 2015, el nivel de la tasa de fondos federales. 


\section{Gráfica 20. Tasa de fondos federales efectiva, 1955-2011}

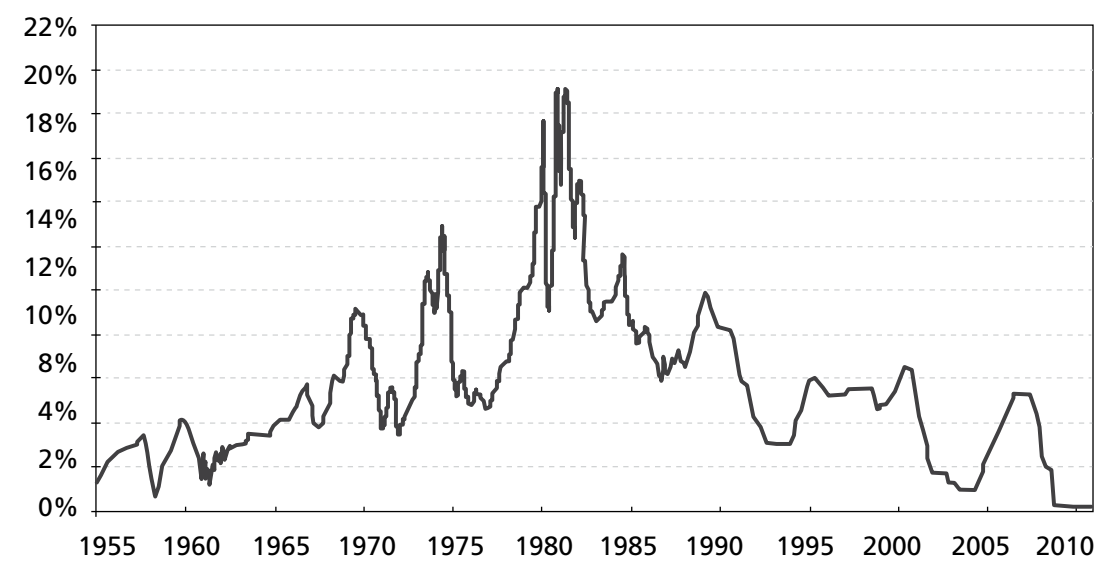

Fuente: Elaboración propia con base en información de MoneyCafe.com (s.f.).

La acción de la Fed y las necesidades de reactivación de las economías provocaron que el resto de países adoptara políticas monetarias flexibles, con tasas de interés que en los desarrollados bajaron al ritmo de la de Eu, al igual que los emergentes, pero con un rezago y una ampliación de la brecha que les permitieron, al menos a partir de 2010, captar una gran cantidad de capital financiero, como sugiere la gráfica 21 para el caso de México.

Gráfica 21. Tasas de interés de política monetaria, enero de 2007-noviembre de 2010

(porcentaje)

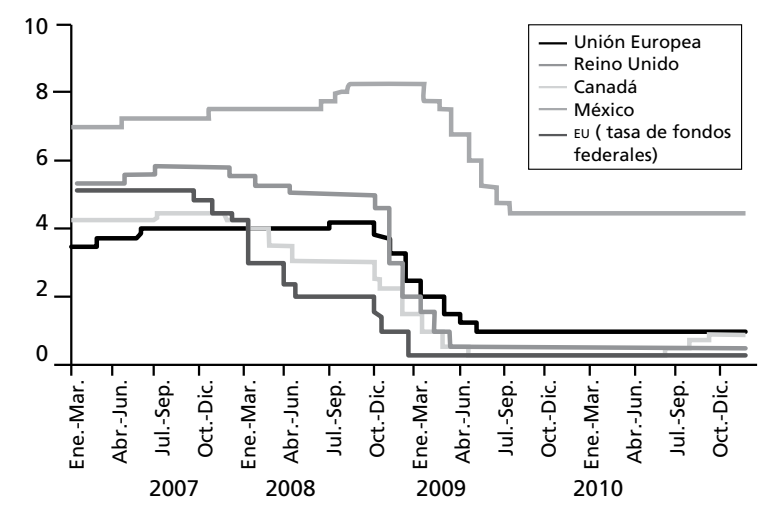

Fuente: Banco de México (2010) con base en cifras de Bloomberg. 
Esto evidencia la contraciclicidad de la política monetaria de este país durante el bienio de la crisis, lo que seguramente incidió en la profundidad con que se vivió ésta en 2009.

A fines de 2010, ya superados los principales problemas de la crisis, el gobierno federal de Eu hizo pública su intención de iniciar un proceso de ahorro a fin de reducir el déficit público, cuya primera medida sería recortar $60000 \mathrm{mi}$ llones de dólares en servicios personales mediante la eliminación de plazas y el congelamiento de las remuneraciones a los funcionarios de alto nivel. Sin embargo, lo que la oposición republicana exigía eran ajustes fundamentales en las áreas de salud, educación y pensiones, en las que se centraba la política social de Obama. Como contrapropuesta, éste solicitó facultades para aumentar los impuestos al gran capital.

La discusión se extendió hasta la víspera del 2 de agosto de 2011, cuando el Congreso autorizó al Ejecutivo, finalmente, una ampliación del techo de endeudamiento del gobierno federal para 2012, anclado en 14.3 billones de dólares (más de 90\% del PNB), sin lo cual se habría parado una parte importante de las actividades del sector público y las calificadoras de inversión habrían retirado el grado de inversión a la deuda soberana estadounidense.

Unos días después, el entonces hombre más rico del país, Warren $\mathrm{Bu}$ ffett, manifestó que no era justo que mientras él pagaba $17.4 \%$ de impuestos sobre sus ingresos gravables, las otras veinte personas que trabajaban directamente con él en su despacho pagaran en promedio 36\%. Con esto, se abrió la posibilidad para que, en el futuro, el Congreso aceptara aumentar los gravámenes al gran capital.

El debate se repitió un año después, al discutirse el presupuesto federal para 2013. En esa ocasión, los republicanos, con mayoría en la Cámara de Representantes, no cedieron y, finalmente, ante la imposibilidad de obtener todos los recursos necesarios mediante un incremento en los impuestos a los contribuyentes con mayor nivel de ingresos, los demócratas y el Ejecutivo aceptaron la puesta en operación de un programa de reducción del gasto público equivalente a un billón 200000 millones de dólares entre marzo de 2013 y diciembre de 2021, incluyendo intereses (CBO, 2013).

La cifra representa $0.8 \%$ del PNB estadounidense promedio anual durante el periodo, a precios de 2013 y para consolidarse implica recortes en el gasto de las agencias federales del orden de 85000 millones de dólares en 2013 y 109000 millones anuales entre 2014 y 2021, sin considerar intereses. Las afectaciones mayores $(-13 \%)$ en 2013 recaen en programas de defensa, mientras los que se 
hallan fuera de esa esfera experimentan recortes de $-9 \%$. Algunos congresistas calcularon que el impacto en el PNB del año sería de 0.6 puntos porcentuales y que se impediría la creación de 750000 nuevos empleos.

En el ámbito internacional se concertó una mayor coordinación con el Grupo de los 20 (G20), que funcionó muy bien en la reunión de 2008 en Londres, pero se desdibujó en la de 2010 en Seúl, sobre todo debido al anuncio de que la Fed relajaría nuevamente su política monetaria, lo que, junto con el nivel excesivamente bajo de la tasa de interés de EU, fue visto por China, Alemania y otras naciones con alto superávit comercial como un debilitamiento deliberado del dólar a fin de devolver competitividad a la economía estadounidense y arrojar más de esta divisa a los mercados del mundo sin importar sus pares del G20.

Esto se confirmó para el caso de diversas economías emergentes desde abril de 2009, como se puede observar en la gráfica 22a, así como para el yen japonés, a partir de octubre de 2010 (gráfica 22b), y para el euro, desde junio de 2010 (gráfica 22c).

\section{Gráfica 22. Tipos de cambio de algunas divisas respecto al dólar de EU, enero de 2007-noviembre de 2010}

a) Divisas de países emergentes Enero de 2007 $=100$

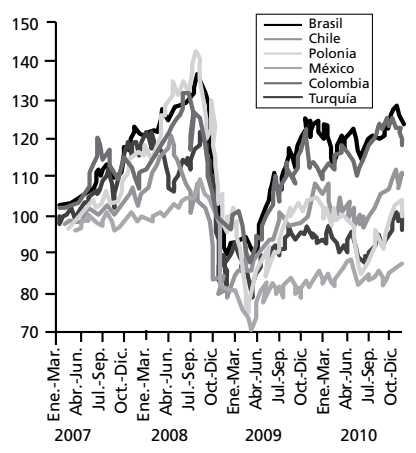

b) Yen

Yenes por dólar

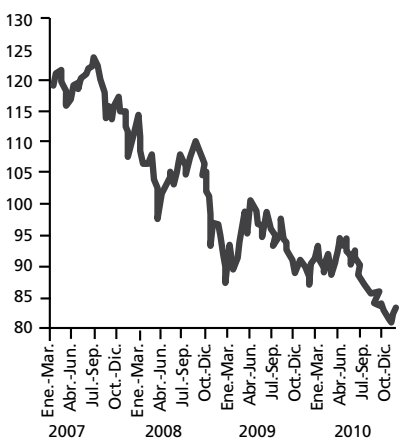

c) Euro

Dólares por euro

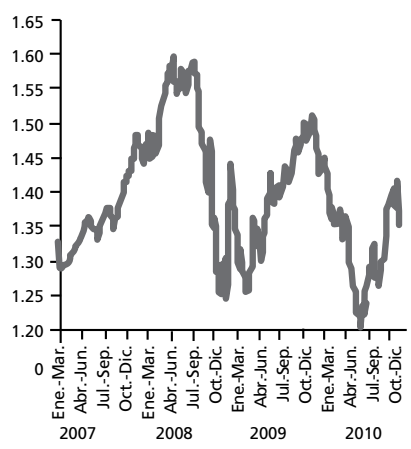

Fuente: Banco de México (2010), con base en cifras de Bloomberg.

Hoy en día, Eu requiere de sus socios comerciales más que nunca, ya que, a pesar de ser la primera economía del mundo, en muchos sentidos ha dejado de ser el motor de la economía global: cada vez ganan más terreno las economías emergentes, particularmente las del grupo BRIC (Brasil, Rusia, India y China), que generaron cerca de la mitad del crecimiento mundial durante los 
primeros 12 años del siglo XXI. Para un periodo más corto, la gráfica 23 muestra que el PNB de estas economías no alcanzó valores negativos durante la recesión, como el resto de regiones (la caída de Rusia y la desaceleración de Brasil fueron más que contrarrestadas con los avances de China e India) y fue el que más rápido se expandió en 2010, después del grupo de "otros".

\section{Gráfica 23. Variación del PNB mundial trimestral, enero de 2007-diciembre de 2010* \\ (porcentaje)}

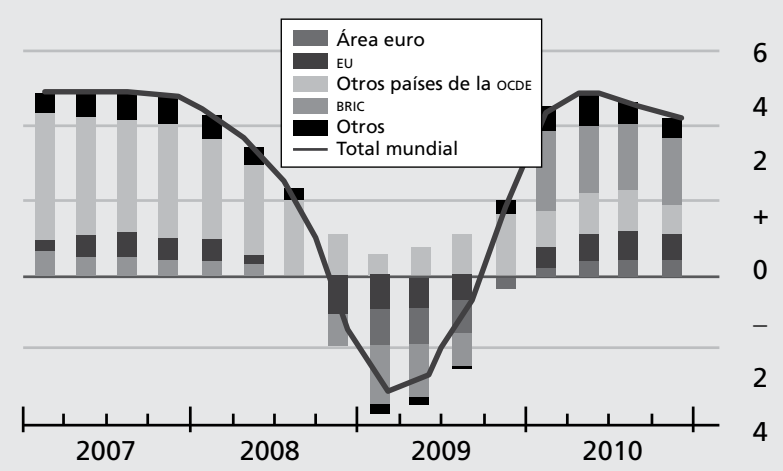

*Estimaciones basadas en 52 países que representan $90 \%$ del PNB mundial con precios a paridad del poder adquisitivo.

Fuente: The Economist (2011).

\section{DE LA CRISIS FINANCIERA AL ALTO Y PERSISTENTE NIVEL DE DESEMPLEO}

Mientras estaba en auge el sistema financiero, entre los años de 2004 y 2007, las ganancias personales e institucionales crecían aceleradamente al mismo tiempo que las tasas de interés se mantenían bajas, lo que hacía que todos los actores se sintieran satisfechos.

Así, siguieron apostando a esta espiral ascendente de ganancias hasta la primera mitad de 2008, a pesar de que por lo menos los banqueros y las más altas autoridades del gobierno federal estdounidense y la Fed se dieron cuenta, desde 2007, que la burbuja financiera explotaría en algún momento. Cuando se hizo evidente que esto iba a suceder, guardaron su dinero, los bancos dejaron de prestarse entre sí y sobrevino el así llamado credit crunch. 
En esta vorágine, las primeras instituciones que se debilitaron, sucumbiendo algunas -aunque la secuencia se dio de manera muy rápida-, fueron los bancos de inversión. En segundo lugar, las calificadoras se retractaron del elevado puntaje que habían otorgado a títulos de dudosa solvencia y composición, como los fondos de protección. En tercer lugar, las aseguradoras empezaron a quedarse sin recursos para respaldar los vehículos especiales de inversión, particularmente los derivados que tomaron como subyacente el valor de los créditos hipotecarios subprime.

En cuarto lugar, cayeron o se descapitalizaron los bancos comerciales generales y especializados en pensiones que otorgaron directamente dichos créditos, quedando inermes frente a los problemas de sus clientes físicos e institucionales. Y en quinto lugar, la cúpula del sector, es decir la Fed y los órganos que directamente dependen de ella, se mostró omisa, evidenciando su escaso control, como habría de reconocer quien fuera su dirigente hasta febrero de 2006, Alan Greenspan (2007), y ratificarían analistas de corte liberal bien documentados (Krugman et al., 2008).

En todo este proceso, el índice Dow Jones, cuyo pico histórico había sido de 14164 puntos, en octubre de 2007, cayó a 6547 puntos en marzo de 2009 , es decir, perdió 54\% de su valor (gráfica 4), equivalente a poco más de 7 billones de dólares, o 50\% del PNB de EU, si se guarda la proporción entre ambas variables reportada en la recesión de 2001-2002 (Gutiérrez, 2004). La cifra es dramática teniendo en cuenta que más de la mitad de los jefes de familia estadounidenses arriesgan su capital en la bolsa de valores, lo que implica que con la recesión no sólo vieron afectada su riqueza, sino que muchos inversionistas se empobrecieron.

Mientras tanto, las instituciones financieras se apartaron de los reflectores, declarándose sin fondos $\mathrm{y}$, por tanto, sin posibilidad de regresar a los ahorradores privados e institucionales al menos una parte de los recursos perdidos. Esta actitud la mantuvieron inclusive cuando recibieron recursos de los fondos de rescate de las administraciones Bush y Obama; de ahí, el malestar de éste, que acusó a los financieros de Wall Street de ser los principales causantes de la crisis, no apoyar la recuperación del poder adquisitivo de los ahorradores y disponer de parte de los recursos recibidos para financiar los bonos de actuación y retiro de sus altos funcionarios: privatizaron las ganancias y socializaron las pérdidas.

Obviamente las cosas no quedaron sólo en la reducción de la capacidad de gasto de las familias por la difuminación de su ahorro. El consecuente credit 
crunch afectó el consumo personal e institucional, la inversión y las necesidades de importación de EU, es decir, los componentes centrales de la demanda efectiva; lo único que quedó como salvación fue el gasto público. La contracción de las compras al exterior, junto con los problemas que vivían países como Reino Unido y en menor medida otros europeos que siguieron el modelo de desregulación financiera estadounidense, así como la escasez global de crédito, hizo que la crisis se internacionalizara, no obstante que a consecuencia de la política monetaria instrumentada los bancos centrales de dichos países mantuvieron baja la tasa de interés de referencia (gráfica 21).

En el sector real de la economía, por su parte, no sólo se redujo el PNB mundial, como se mostró en la gráfica 23 , sino que desde la conclusión de la segunda Guerra Mundial el volumen de bienes comerciados sufrió la más importante contracción, $-11.0 \%$ (IMF, 2010).

Es decir, existe una cadena de causalidad en las crisis que tiende a repetirse una y otra vez: primero se registra un periodo de exuberancia financiera, con tasas de interés muy bajas y alta inversión en instrumentos de riesgo, que van desde acciones cotizadas en el mercado bursátil hasta otros cuya naturaleza tiende a cambiar con el tiempo, dependiendo de lo omisas que sean las autoridades financieras.

Gráfica 24. Tasa de desempleo de Estados Unidos, enero 2000-marzo 2013 (porcentaje)

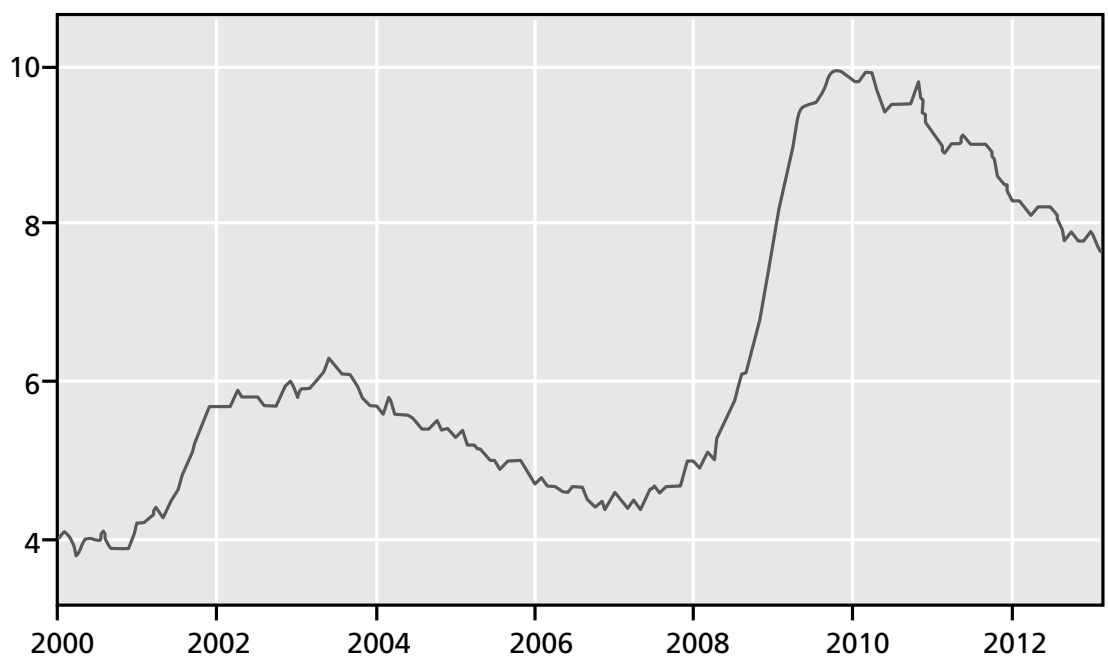

Fuente: Elaboración propia con base en us Bureau of Labor Statistics (s.f.). 
Posteriormente, cuando se percibe y generaliza el riesgo implícito en los instrumentos de renta variable, los mercados financieros locales en su conjunto se deprimen, las tasas de interés son presionadas al alza, se reduce el crédito interbancario y con éste las posibilidades de financiamiento tanto al consumo como a la inversión. Dadas las correas de transmisión que impone la globalización, dicha secuencia afecta los mercados financieros del resto del mundo.

El proceso anterior repercute, en segunda instancia, en la capacidad de consumo no solameante del o los países que originan la crisis, sino también de sus principales socios comerciales. Al resultar contaminada la economía real, se generaron -en tercera instancia-, inventarios indeseados, sobre todo de bienes duraderos y suntuarios, los cuales no pueden ser vendidos ni en el interior ni en el exterior. Esto provoca, en cuarta instancia, que se contraigan el comercio y el producto mundiales. Por último, tuvo lugar un deterioro del mercado de trabajo por dos vías: la caída de los salarios reales y la disminución de las oportunidades de empleo.

Para el caso de Eu, la tasa desestacionalizada de desempleo se situó, en octubre del año de 2009, en su nivel máximo durante la crisis: $10.0 \%$, es decir, casi cuatro puntos porcentuales por arriba del nivel pico alcanzado como secuela de la recesión de 2001-2002. A partir de ese nivel, inició un descenso que la llevó hasta $8.8 \%$ en abril de 2011; volvió a subir a $9.1 \%$ en junio, julio y agosto del mismo año, debido a un debilitamiento de la actividad económica, y retomó su descenso para situarse en $8.2 \%$ en marzo de 2012 y $7.6 \%$ en igual mes de 2013 (gráfica 24).

Evidentemente, la corrección del mercado laboral en tiempos de crisis no es una cosa fácil. Por ello, para ser capaces de visualizar la importancia de las correcciones que ha seguido la Fed desde el inicio de la crisis, es un ejercicio altamente significativo elaborar una gráfica en la que se relacione en un plano cartesiano la ocupación (variable independiente, en el eje de las abcisas) con la tasa de interés (variable dependiente, en el eje de las ordenadas), aunque los resultados de dichas correciones no necesariamente son los mismos en Europa, donde los mercados laborales son más rígidos.

Si se asume que la tasa de interés es perfectamente flexible y, por tanto, capaz de eliminar el desempleo no deseado, así como, en su caso, el exceso de demanda de fuerza de trabajo más allá del pleno empleo, la oferta de mano de obra deberá representarse como un línea perfectamente inelástica (vertical) y la demanda como una línea de pendiente negativa. En este marco, una tasa de interés alta hace que se pospongan decisiones de inversión y consumo y que el 
producto y la ocupación sean bajos; una tasa baja actúa en sentido contrario. Esto puede visualizarse en la gráfica 25 .

\section{Gráfica 25. Exceso de oferta de mano de obra resultante de establecer una tasa de interés real superior al nivel de equilibrio}

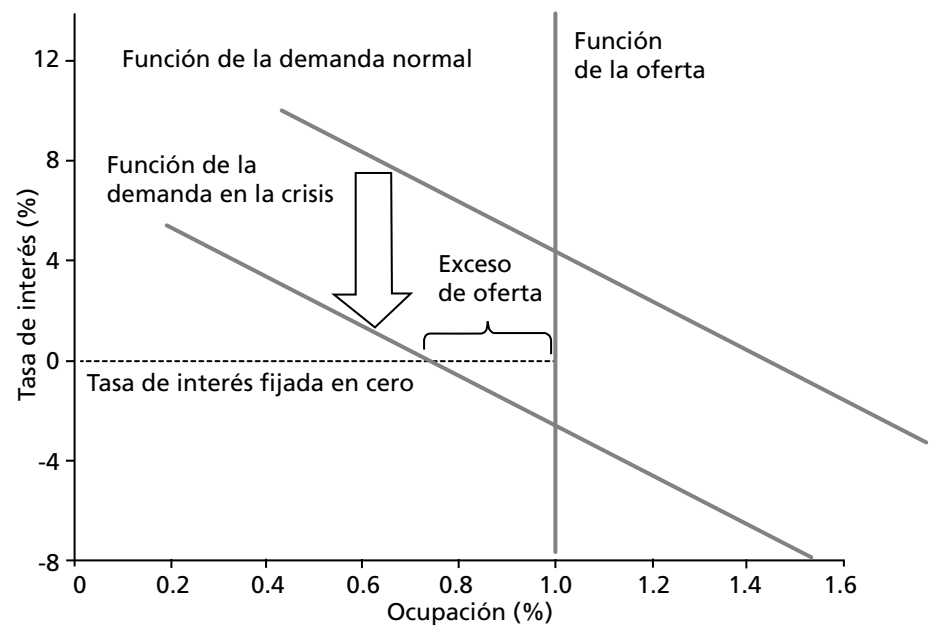

Fuente: Hall (2011).

Cuando la economía enfrenta una crisis, ya sea por el lado de la oferta, como sucede con las crisis financieras, que contraen el crédito, o por el lado de la demanda, debido a reducciones en el consumo, la inversión, el gasto de gobierno y/o las exportaciones, la curva de demanda de mano de obra se mueve hacia abajo e intersecta a la de la oferta en un punto en que la tasa de interés es mucho más baja, a fin de propiciar el reequilibrio del mercado laboral. Es decir, sigue la secuencia de la flecha de la gráfica, que muestra el traslado de una función de demanda de mano de obra en condiciones normales a otra en condiciones de crisis. A partir de esta lógica, el colapso en la construcción de casas habitación durante la crisis de 2008-2009 busca compensarse a través, por ejemplo, de incrementos en los niveles de inversión y consumo de productos no durables. ${ }^{19}$

\footnotetext{
${ }^{19}$ Por supuesto, la devolución de impuestos a las familias, las ofertas por parte de las tiendas comerciales, como el Black Friday, la reducción de impuestos a los productores y la recapitalización de las instituciones financieras fueron acciones que actuaron en la misma dirección. Es decir que el programa de medidas correctivas del gobierno estadounidense mezcló políticas fiscales con políticas monetarias; no se trató, por tanto, de un programa de rescate exclusivamente keynesiano, como ha tendido a argumentarse.
} 
Entonces, la reducción de la tasa de interés tiene la capacidad de actuar como un restaurador del mercado de mano de obra; pero ¿cuáles son sus verdaderos alcances? La tasa de interés nominal más baja posible es cero; así, la tasa de interés real más baja debe ser menor a la tasa de inflación. En el peor caso posible, la Gran Depresión de 1929-1932, el nivel de precios se redujo durante varios años consecutivos y la tasa real de interés se siguió fijando en un nivel positivo. La gráfica 25 muestra de manera simple la implicación de fijar en cero la tasa real de interés, en vez de ubicarla en $-2.5 \%$. Con una tasa cero se aprecia un exceso de oferta de fuerza de trabajo, que se transforma en desempleo (Hall, 2011, pp. 433-434).

Lo anterior ayuda a comprender por qué la tasa de interés de fondos federales de eu se ha mantenido en $0.25 \%$ desde fines de 2010: dicho nivel implica una tasa de interés real de alrededor de $-2.0 \%$, considerando que la inflación promedio anual del país ha oscilado alrededor de $2.3 \%$ a partir de $2010 .{ }^{20}$ Aun así, la tasa de desempleo sigue siendo alta y altas tasas de desempleo conducen, en última instancia, a aumentos de la pobreza, la desigualdad y la exclusión social; de ahí, la importancia de concentrar esfuerzos en su abatimiento (OECD, 1994).

En la práctica, la tasa de interés es insuficiente para corregir los problemas del mercado laboral por una simple y sencilla razón: el hecho de que el crédito sea barato y los productores estén dispuestos a recurrir a los banqueros para solicitarlo no implica que éstos lo van a otorgar.

Ante la dificultad de los gobiernos para obligar a los bancos a otorgar créditos, la política económica recurre a diversas acciones paralelas: a) el estímulo al consumo mediante la reducción de impuestos (medida que no funciona si las familias optan por ahorrar esos recursos, como sucedió en Japón durante la recesión de los noventa, supuestamente por encontrarse la economía cerca de una trampa de liquidez); b) el estímulo a la producción de las empresas y, por tanto, a su capacidad de seguir empleando gente, mediante la reducción de impuestos; c) el aumento del gasto público en rubros de carácter social y de defensa; d) la mayor circulación de dinero mediante operaciones de mercado abierto, e) la recapacitación de los trabajadores por parte de las instancias gubernamentales, y f) la depreciación inducida de la moneda local para devolver competitividad a las exportaciones.

${ }^{20}$ Se parte de la fórmula $T R=[(1+T N)-(1+T I)] / 1+T I$, donde: $T R$, tasa de interés real; $T N$, tasa de interés nominal, y $T I$, tasa de inflación. 


\section{CONCLUSiones}

A lo largo de este trabajo se ha tratado de mostrar cómo la desregulación financiera en EU y otros países, la globalización del comercio y las finanzas mundiales, y la reducción de las tasas de interés a partir de 2002 se constituyeron en las causas principales de la crisis de 2008-2009. Una crisis que, a pesar de las características que le otorga su contemporaneidad, guarda enormes similitudes con las que se padecieron durante el siglo Xx y principios del XXI.

En la etapa inmediatamente anterior a la crisis se observa una enorme euforia por parte de los agentes económicos, que ante la gran liquidez del sistema y las bajas tasas de interés de los instrumentos tradicionales optan por la inversión en instrumentos de alto riesgo, muchos de ellos sin suficiente regulación y emitidos por instituciones débilmente capitalizadas. En la etapa de crisis se produce una pérdida repentina de confianza, las instituciones más débiles quiebran, caen los mercados financieros, el crédito deja de fluir, suben las tasas de interés, se afectan los precios de las materias primas, se contrae la demanda agregada, se reduce el comercio y cae el producto mundial. En la etapa avanzada se ponen en práctica programas de rescate de empresas financieras y no financieras quebradas, se ajustan las políticas fiscal y monetaria y, al hacerse evidente la persistencia del desempleo, se refuerzan las políticas activas de empleo. Empero, la desocupación sigue aumentando y alcanza sus niveles máximos en una etapa posterior, es decir, cuando la economía da muestras de iniciar su recuperación; si aquélla no entra en doble recesión, en algún punto posterior se inicia el descenso de la tasa de desempleo, aunque de manera parsimoniosa, en concordancia con la reactivación de la inversión productiva.

La experiencia de esta crisis es que, además de haber sido muy prolongada, los patrones de comportamiento regional han variado mucho. Por una parte, en el continente americano prácticamente todos los países tuvieron un solo año de contracción del producto (en 2009) y al siguiente ya habían regresado a los niveles de producción prevalecientes en 2008. Las excepciones fueron EU, México y algunas naciones del Caribe, donde la recesión duró alrededor de 18 meses y el retorno del producto a los niveles de 2008 no se alcanzó hasta 2011.

Por otro lado, Europa en su conjunto ha enfrentado una situación sui generis, con muchos países experimentando recesión en 2008 y 2009, y sufriendo recaídas (doble recesión) en 2011 o 2012, después de que en 2010 parecía haberse iniciado la recuperación. Los casos más señalados han sido los de España, 
Italia, Irlanda, Portugal, Reino Unido, Bélgica, Dinamarca y Francia. Como casos extremos de estos comportamientos se hallan Grecia, cuyo producto no ha logrado recuperarse desde 2008, y Alemania, que después de una contracción en 2009 se pudo mantener permanentemente en niveles positivos y dinámicos. Este último, además, impulsó la aplicación de los programas de ajuste en la Unión Europea, al tiempo que se esforzó por preservar la cohesión de ésta y la sustentabilidad del euro.

Si EU comparte con Europa y Japón problemas similares en materia de endeudamiento, cabe preguntarse ¿por qué la crisis afectó más a Europa? Aparentemente, las razones que más influyeron fueron la falta de flexibilidad laboral de este continente, sus mayores costos de producción, la condición de sus países de seguidores más que de líderes tecnológicos y el peso de la Unión Europea, que maniató la política monetaria y cambiaria en países a los cuales su manejo discrecional habría permitido resolver varios problemas.

Una región aparte es Asia, a la que en general la crisis no tocó, ya que con excepción de Japón, que también tuvo doble caída, y Malasia, que se contrajo ligeramente en 2009, en el resto de países se gozó de tasas muy elevadas de crecimiento, sobre todo en China, India, Australia y República de Corea. En estos países, cabe recordar, la integración regional no limita las políticas monetaria y cambiaria, y el Estado actúa como un agente más de la actividad industrial y comercial.

Uno de los principales saldos de la crisis financiera de 2008-2009 es que contribuyó a aumentar los altos déficit fiscal y en cuenta corriente de los países desarrollados, de por sí proclives a endeudarse; ésta puede ser la principal razón de que aún en 2013 no lograran consolidar su recuperación. Evidentemente, el peso sobre sus finanzas públicas y su competitividad, debido a que sus gobiernos tuvieron que seguir acciones de estímulo a la inversión y el consumo, implicaron costos muy altos. Por ejemplo, al cubrirse el déficit gubernamental de EU con deuda interna y externa, mediante la colocación de bonos del Tesoro en todos los países del mundo que pudieron y estuvieron dispuestos a adquirirlos, el gobierno estadounidense dejó a los contribuyentes una carga que, a juzgar por la tendencia iniciada desde el primer gobierno de Bush y continuada por el de Obama, no se saldará antes de 2021. Así parece corroborarlo la primera corrección presupuestal significativa del siglo, acordada por la Cámara de Representantes en marzo de 2013. En términos estrictos, la reducción de un billón 200000 millones de dólares de gasto público, incluyendo intereses, entre 2013 y 2021, implica una estrategia de congelamiento del nivel de la deuda pública y del déficit en términos 
nominales dejando que su coeficiente respecto al PNB baje paulatinamente (se "licúe") en términos reales, hasta volverse manejable.

Una medida complementaria, a la que aún no recurre el gobierno estadounidense, es la depreciación del dólar, que cuando sobrevenga generará roces con los principales países superavitarios del mundo, que son tenedores de bonos del Tesoro -China, Japón, Brasil, las economías petroleras-, ya que con ello no sólo les comprará menos mercancías, sino que reducirá el valor real de su deuda. Esta medida es previsible en virtud de que, como consecuencia de la crisis, muchos gobiernos se quejaron entre 2010 y 2012 de desequilibrios cambiarios y llevaron la discusión al seno de la OMC, sin que el problema llegara a resolverse. Aunque el principal foco de atención es China, cuyo grado de subvaluación de su moneda desestimula el consumo interno, lo que podría favorecer la aplicación de medidas similares por parte, al menos, de los dos países que más se han quejado de este problema: Eu y Brasil.

Coeficientes de endeudamiento cercanos a $100 \%$ del PNB y niveles de déficit del sector público de casi $4 \%$ en la mayoría de países desarrollados desalientan a los inversionistas. En otros términos, aun suponiendo que las instituciones financieras causantes de la crisis ya estuvieran plenamente capitalizadas -lo cual es discutible-, que se respetaran los acuerdos de Basilea II y los de Basilea III se encontraran operando, y que se hubiera restablecido el sistema de pagos a plenitud, la iniciativa privada de los países desarrollados seguiría siendo escéptica respecto a invertir en ellos. Esto explica por qué dichos inversionistas siguieron optando, hasta 2013, por tasas de interés altas en los mercados financieros de los países emergentes, en vez de promover la inversión productiva en sus propias economías.

De una manera $u$ otra, los efectos de los programas de ajuste, aunque dolorosos en el corto plazo, tenderán a rendir frutos a partir de mediados de 2014, año para el que se prevé que todas las regiones y países del mundo retornen a una senda expansiva, en el marco de un crecimiento mundial posiblemente superior a 2\%, como no sucede desde 2010 (IMF, 2013). Esto, sin embargo, debe tomarse con reservas, ya que dicho crecimiento podría no ser estable, como sucedió en 2011-2012, después de la euforia expansiva de 2010.

Además, el problema de tasas pico de desempleo en Europa, sobre todo en la región mediterránea e Irlanda, persistirá por lo menos hasta fines de 2013: España, 27\%; Portugal, 18\%; Irlanda, 14.5\%; Italia, 12\%, y Francia, 11\% (OECD, 2013). De acuerdo con la experiencia, el retorno a niveles de desempleo simila- 
res a los de antes de la crisis de 2008-2009 podría tomar hasta 24 meses después del pico de 2013. En otros términos, lo más probable es que en la esperada fase de recuperación de la economía global se repita en Europa el problema que se vivió después de la recesión de 1992-1993, conocido como periodo de crecimiento con desempleo (OECD, 1994).

\section{REFERENCIAS BIBLIOGRÁFICAS}

Aizenman, Joshua (2009), "Financial Crisis and the Paradox of Under-and-Over-Regulation", NBER Working Paper 15018, mayo.

American Recovery and Reinvestment Act (2009), s.l., s.e. (PDF). Disponible en: http:// www.law.cornell.edu/jureeka/index.php?doc $=$ USPubLaws\&cong=111\&no=5. Consultado en diciembre de 2009.

Banco de México (2009), Reporte sobre el sistema financiero. Julio, México, Banco de México.

- (2010), Reporte sobre el sistema financiero. Junio, México, Banco de México. Barajas, Adolfo; Chami, Ralph; Casimano, Thomas, y Hakura, Dalia (2010), "us Bank Behavior in the Wake of the 2007-2009 Financial Crisis", IMF Working Paper $10 / 131$.

Barro, Robert J., y Urzúa, José F. (2009), "Stock-market crashes and Depressions”, NBER Working Papers 14760, febrero.

BEA (s.f.a), "GDP and Personal Income", en us Bureau of Economic Analysis. Consultado en junio de 2011 en: http://www.bea.gov/itable/.

_ (s.f.b), "National Income and Product Accounts Tables", en us Bureau of Economic Analysis. Consultado en noviembre de 2011 en: http://www.bea.gov/ iTable/iTable.cfm?ReqID=9\&step=1\#reqid=9\&step=1\&isuri=1.

Board of Governors of the Fed (s.f.), "Flows of Funds Accounts of the United States", en Board of Governors of the Federal Reserve System. Consultado en junio 2009 en: http://www.federalreserve.gov/apps/fof/FOFTables.aspx.

Boyer, Robert (2012), "Alternativas teóricas a la crisis económica actual”, seminario impartido a académicos de la Universidad Autónoma Metropolitana-Iztapalapa, México, DF, 4 al 8 de junio.

Braudel, Fernand (1979), Civilisation Matérialle, Economie et Capitalism, XVe-XVIIe Siecle, Paris, Armand Colin.

сво (2013), Congressional Budget Office. Disponible en: www.cbo.gov. CEPAL (2010), Panorama de la inserción de América Latina y el Caribe 2009-2010. Crisis 
originada en el centro y recuperación impulsada por las economías emergentes, Santiago de Chile, Comisión Económica para América Latina y el Caribe.

(2011), "Volatilidad de precios en los mercados agrícolas (2000-2010). Implicaciones para América Latina y opciones políticas", Boletín CEPAL/FAO/ICA, núm. 1, pp. 1-36.

Coello, Felipe (2011), "Yo sobreviví a Lehman”, Expansión, 18 de julio, núm 1070, pp. 86-92..

Correa, Ma. Antonia, y Gutiérrez R., Roberto (2004), “Ataques terroristas y recesión en Estados Unidos”, en Graciela Pérez Gavilán y Ana Teresa Gutiérrez del Cid (coords.), Pensar la guerra: hacia una nueva geopolítica mundial, México, Editorial Quimera/UAM-X.

Crotty, James (2008), "Structural causes of the global financial crisis: A critical assessment of the New Financial Arquitecture”, PERI Workingpaper Series 180, University of Massachusetts Amhest.

Dabat, Alejandro (2009), "La crisis financiera en Estados Unidos y sus consecuencias internacionales", Problemas del Desarrollo, vol. 40, núm. 157, abril-junio, pp. 39-74.

Dymski, Gary A. (2007), From financial exploitation to global banking instability: Two overlooked roots of the subprime crisis, s.l., s.e. [PDF] Disponible en: http:// www.soas.ac.uk/economics/events/crisis/file43938.pdf. Consultado en abril de 2013.

Estevadeordal, Antoni, y Taylor, Alan M. (2008), "Is the Washington Concensus Dead? Growth, Openess, and the Great Liberalization, 1970s-2000s", NBER Working Paper 14264, agosto.

Executive Office of the President y Council of Economic Advisers (2010a), Economic Report of the President 2010, Washington, us Government Printing Office.

(2010b), The Economic Impact of the American Recovery and Reinvestment Act of 2009, Fifth Quarterly Report, Washington, DC, Executive Office of the President/Council of Economic Advisers.

- (2011), Economic Report of the President 2011, Washington, Us Government Printing Office.

Fed (s.f.), "Senior Loan Officer Opinion, Survey of Bank Lending Practices. 2009”, en The Federal Reserve Board. Consultado en junio de 2009 en: http://www.federal reserve.gov/boarddocs/SnLoanSurvey/default.htm.

Financial Crisis Inquiry Commission (2011), The Financial Crisis Inquiry Report, Washington, us Government Printing Office. 
G20 (2010), “The G20 Seoul Summit Leaders' Declaration”, en G20 Information Centre. Consultado en febrero de 2013 en: http://www.g20.utoronto.ca/2010/g20seoul. html.

Galbraith, John K. (1976), El crac del 29, Barcelona, Ariel.

Greenspan, Alan (2007), The Age of Turbulence. Adventures in a New World, New York, Penguin Books.

Gutiérrez R., Roberto (1993), Los avatares de la deuda externa de México, México, UAM-X.

- (2002), "La globalización: retos, oportunidades y tendencias", en María Antonia Correa Serrano y Roberto Gutiérrez R. (coords.), Tendencias de la globalización en el nuevo milenio, México, Uam-X, pp. 13-47.

— (2004), "El papel de la industria de las TIC: recesión y recuperación en Estados Unidos y México, Análisis Económico, vol. xIx, núm. 42, pp. 45-77.

Hall, Robert E. (2011), "Why does the economy falls to pieces after a financial crisis?", Journal of Economic Perspectives, vol. 24, núm 4, pp. 3-20.

Hanson, Samuel G.; Kashyap, Anil K., y Stein, Jeremy C. (2011), "A macroprudential approach to financial regulation", Journal of Economic Perspectives, vol. 25, núm. 1, pp. 3-28.

Iglesias-Sarría, Cristina, y Vargas, Fernando (2010), "Entidades financieras sistémicas: discusión de posibles medidas", Estabilidad Financiera, mayo, núm. 18.

IMF (2010), World Economic Outlook. October 2010. Recovery, Risk and Rebalancing, Washington, International Monetary Fund.

_ (2013), World Economic Outlook. April 2013. Hopes, Realities, Risks, Washington, International Monetary Fund.

IMF Fiscal Monitor (2010), Navigating the Fiscal Challenges Ahead, Washington, International Monetary Fund.

Jagannathan, Ravi; Kapoor, Mudit, y Schaumburg, Ernst (2009), "Why are we in a recession? The financial crisis is a symptom, not the disease!", NBER Working Paper 15404 , octubre.

Kacef, Osvaldo, y López-Monti, Rafael (2010), “América Latina, del auge a la crisis: desafíos de política macroeconómica", Revista de la CEPAL, abril, núm 100, pp. 41-68.

Krugman, Paul, et al. (2008), La crisis económica mundial, México, Debate.

Larraín, Felipe, y Sachs, Jeffrey (2002), Macroeconomía en la economía global, segunda edición, Buenos Aires, Prentice Hall.

Mian, Atif; Sufi, Amir, y Trebbi, Francesco (2010), "The Political Economy of the Subprime Mortage Credit Expansion”, NBER Working Paper 16107, junio. 
Mishkin, Frederic S. (2011), "Over the Cliff: From the Subprime to the Global Financial Crisis", Journal of Economic Perspectives, vol. 25, núm 1, pp. 49-70.

MoneyCafe.com (s.f.), "Federal funds rate", en MoneyCafe.com. Consultado en diciembre de 2011 en: http://www.moneycafe.com/personal-finance/fed-funds-rate/.

Mortgage-X (s.f.), "Interest Rate Trends", en Mortgage Information Service. Consultado en junio de 2011 en: http://mortgage-X.com/trends.htm.

NBER(2010), “The Business Cycle Dating Committee, National Bureau of Economic Research", en The National Bureau of Economic Research. Consultado en: http:// www.nber.org/cycles/sept2010.html.

OECD (1994), The OECD Jobs Study. Evidence and Explanations, Paris, Organisation for Economic Co-operation and Development.

- (2011), Harmonized Unemployment Rates. February 2011, París, Organisation for Economic Co-operation and Development.

- (2013), Harmonized Unemployment Rates. March 2013, París, Organisation for Economic Co-operation and Development.

- (s.f.), "Revenue Statistics - Comparative tables", en oECD.StatExtracts. Consultado en diciembre de 2010 en: http://stats.oecd.org/Index.aspx?DataSet Code $=$ REV.

Parsons, J. (2011), "Real Estate Charts", en JP's. Consultado en febrero de 2011 en: http://www.jparsons.net/housingbubble/.

Pérez, Carlota (2004), Revoluciones tecnológicas y capital financiero. La dinámica de las grandes burbujas financieras y las épocas de bonanza, México, Siglo XXI.

PNUD (2010), Informe sobre Desarrollo Humano 2010, Nueva York, Programa de las Naciones Unidas para el Desarrollo.

Radalet, Steven, y Sachs, Jeffry (1998), “The onset of the East Asian Financial crisis", NBER Working Paper 6680, agosto.

Reinhart, Carmen M. y Rogoff, Kenneth S. (2008), “Is the 2007 us Sub-prime financial crisis so different? An international historical comparison", NBER Working Paper 13761, enero.

Reinhart, Vincent (2011), “A year of living dangerously: The management of financial crisis in 2008", The Journal of Economic Perspectives, vol. 25, núm. 1, pp. 71-90.

Rodrik, Dani, y Subramanian, Arvind (2009), "Why did financial globalization disappoint?”, IMF Staff Papers 56, enero.

(2009), "Growth after the crisis", CEPR Discussion Papers 7480, mayo.

Roubini, Nouriel (2007), "“The Biggest Slump in Us Housing in the Last 40 Years... or 53 Years", en Roubini Global Economics. Disponible en: www.rgemonitor.com/ blog/roubini/142759/ 
Temin, Peter (2010), “The Great Recession and the Great Depression”, NBER Working Paper 15645, enero.

The Economist (2011), con base en cifras del Banco Mundial (2012), World Development Indicators. Consultado en octubre de 2011 en: http://data.worldbank.org/ products/wdi.

UnCTAD (2010), Trade and Development Report 2010, Geneva, United Nations Conference on Trade and Development.

us Bureau of Labor Statistics (s.f.), "Unemployment Statistics", en Labor Force Statistics from the Current Population Survey. Consultado en junio de 2013 en: http:// www.bls.gov/cps/lfcharacteristics.htm\#unemp.

us Census Bureau (2008), State of the Nation's Housing Report, Washington, us Census Bureau.

Volcker, Paul (2010), entrevistado en Foro TV por Guillermo Ortiz (televisión), Televisa, 29 de diciembre.

Wall, Robert E. (2011), “The long slump”, American Economic Review, vol. 101, núm. 2, pp. 431-469.

Ward, Karen (2011), The World in 2050. Quantifying the Shift in the Global Economy. London, HSBC Global Research. 